\title{
Angiotensin II regulates phosphorylation of actin-associated proteins in human podocytes
}

\author{
Laura K. Schenk, ${ }^{*, 1}$ Annika Möller-Kerutt, ${ }^{*, 1}$ Rafael Klosowski, ${ }^{+, 1}$ Dirk Wolters, ${ }^{+}$ \\ Elisabeth Schaffner-Reckinger, ${ }^{*}$ Thomas Weide, ${ }^{*}$ Hermann Pavenstädt, ${ }^{*, 1}$ and Beate Vollenbröker, ${ }^{*, 1,2}$ \\ ${ }^{*}$ Medizinischen Klinik und Poliklinik D, Universitätsklinikum Münster, Munster, Germany; ${ }^{+}$Analytische Chemie, Biomolekulare \\ Massenspektrometrie, Ruhr-Universität Bochum, Bochum, Germany; and ${ }^{\ddagger}$ Laboratory of Cytoskeleton and Cell Plasticity, Life Sciences \\ Research Unit, University of Luxembourg, Esch-sur-Alzette, Luxembourg
}

\begin{abstract}
Within the kidney, angiotensin II (AngII) targets different cell types in the vasculature, tubuli, and glomeruli. An important part of the renal filtration barrier is composed of podocytes with their actin-rich foot processes. In this study, we used stable isotope labeling with amino acids in cell culture coupled to mass spectrometry to characterize relative changes in the phosphoproteome of human podocytes in response to short-term treatment with AngII. In 4 replicates, we identified a total of 17,956 peptides that were traceable to 2081 distinct proteins. Bioinformatic analyses revealed that among the increasingly phosphorylated peptides are predominantly peptides that are related to actin filaments, cytoskeleton, lamellipodia, mammalian target of rapamycin, and MAPK signaling. Among others, this screening approach highlighted the increased phosphorylation of actin-bundling protein, L-plastin (LCP1). AngII-dependent phosphorylation of LCP1 in cultured podocytes was mediated by the kinases ERK, p90 ribosomal S6 kinase, PKA, or PKC. LCP1 phosphorylation increased filopodia formation. In addition, treatment with AngII led to LCP1 redistribution to the cell margins, membrane ruffling, and formation of lamellipodia. Our data highlight the importance of AngII-triggered actin cytoskeleton-associated signal transduction in podocytes.-Schenk, L. K., Möller-Kerutt, A., Klosowski, R., Wolters, D., Schaffner-Reckinger, E., Weide, T., Pavenstädt, H., Vollenbröker, B. Angiotensin II regulates phosphorylation of actin-associated proteins in human podocytes. FASEB J. 31, 000-000 (2017). www.fasebj.org
\end{abstract}

KEY WORDS: kidney $\cdot$ L-plastin $\cdot$ actin turnover $\cdot$ calcium

The glomerular filtration barrier in the kidney is among those composed of podocytes with interdigitating actinbased processes. These podocyte foot processes with the interposed slit diaphragm play an important role in maintaining the selective permeability of the glomerular filtration barrier that retains large proteins but freely filters water, electrolytes, and small molecules (1). During the last decade, it has become clear that podocyte injury is associated with proteinuria (1-3).

The peptide hormone, angiotensin II (AngII), is a major component of the renin-angiotensin-aldosterone system (RAAS) and, thus, a crucial regulator of blood pressure, salt-water balance, sympathetic nervous system, and

\footnotetext{
ABBREVIATIONS: AngII, angiotensin II; AT1R, angiotensin II receptor type 1; LCP1, L-plastin; RAAS, renin-angiotensin-aldosterone system; RFP, red fluorescent protein; RSK, p90 ribosomal S6 kinase; SILAC, stable isotope labeling with amino acids in cell culture; WT, wild type

${ }^{1}$ These authors contributed equally to this work.

${ }^{2}$ Correspondence: Medizinischen Klinik und Poliklinik D, Albert Schweitzer Campus 1, A14, D-48149 Münster, Germany. E-mail: beate.vollenbroeker@ ukmuenster.de
}

doi: 10.1096/fj.201700142R

This article includes supplemental data. Please visit $h t t p: / / w w w$ fasebj.org to obtain this information. tissue homeostasis (4). AngII mediates the vasoconstriction of the efferent glomerular arteriole, thereby physiologically regulating the glomerular filtration rate (5). High levels of AngII and sustained RAAS activation are crucial factors in the pathogenesis of glomerular injury (6), and AngII is a major profibrotic cytokine that leads to glomerulosclerosis (7). Clinical studies have proven that AngII receptor 1 (AT1R) blocker and angiotensin-converting enzyme inhibitors have a beneficial effect on proteinuria and inhibit the progression of kidney disease (8). Indeed, administration of these drugs is associated with lower mortality in patients with chronic kidney disease (9).

The AngII receptor, AT1R, is a GPCR. Upon receptor activation via AngII stimulation, the intracellular $C$ terminus of AT1R couples to $G$ proteins, such as $G_{q / 11}, G_{i}$, $\mathrm{G}_{12}$, and $\mathrm{G}_{13}$, thereby inducing various second messenger pathways, such as PLC/inositol trisphosphate, reactive oxygen species, calcium, and protein kinase signaling (10, 11). It has also been shown that AngII has direct effects on the actin cytoskeleton rearrangement of podocytes. The integrity of the actin cytoskeleton is important for the physiologic function of podocytes, and actin cytoskeleton deregulation may result in podocyte disease (12); 
however, the molecular details of AngII-dependent signaling cascades in podocytes are not yet fully understood. In this study, we focused on AT1R-mediated protein kinase signaling and investigated which phosphorylation sites were regulated during short-term treatment with AngII in AT1R-expressing human podocytes.

Our data analyses revealed an over-representation of actin-associated proteins among regulated phosphorylation sites. Among other proteins, AngII stimulation induced the phosphorylation of L-plastin (LCP1). The actin bundling protein, LCP1, is known for its important role in the regulation of the actin cytoskeleton of leukocytes and solid tumor cells (13), and we now can add several novel aspects of LCP1 regulation in podocytes.

\section{MATERIALS AND METHODS}

\section{Cell culture and stable isotope labeling with amino acids in cell culture}

Human immortalized podocytes (AB8/13; kindly provided by M. Saleem, School of Clinical Sciences, University of Bristol, Bristol, United Kingdom), the Retro-X packing cell line GP2-293, and HEK293 cells (Thermo Fisher Scientific, Waltham, MA, USA) were cultivated at standard conditions as previously described $(14,15)$. Generation and characterization of stably transfected AB8 3F-AT1R cell lines has been previously described (14). For relative quantification of the phosphoproteome, AB8 3F-AT1R podocytes were grown in stable isotope labeling with amino acids in cell culture (SILAC) (16) culture medium that contained amino acids arginine and lysine labeled with stable isotopes (heavy: $\left[{ }^{13} \mathrm{C}\right]_{6}\left[{ }^{15} \mathrm{~N}\right]_{4}$ arginine, $\left[{ }^{13} \mathrm{C}\right]_{6}$ lysine; light: $\left[{ }^{12} \mathrm{C}\right]_{6}\left[{ }^{14} \mathrm{~N}\right]_{4}$ arginine, $\left[{ }^{12} \mathrm{C}\right]_{6}$ lysine) for 3 passages. This labeling period is sufficient to achieve $>98 \%$ saturation of labeling (17). On the day of the experiment, 1 set of cells was treated with AngII (100 nM for 15 min; Sigma-Aldrich, St. Louis, MO, USA), another with vehicle, and then samples were pooled 1:1 (AngII/vehicle). In 2 biological replicates, cells that were grown in medium with heavy isotopes of amino acids were treated with AngII, and in 2 replicates cells that were grown in light isotopes were treated.

\section{Sample purification and liquid chromatography-tandem mass spectrometry}

After filter-aided sample preparation (18), $\mathrm{TiO}_{2}$ microcolumn phosphopeptide enrichment was performed (19). Samples were loaded on MudPIT columns as previously descibed (20). Kinetex $\mathrm{C}_{18}$ (Phenomenex, Torrance, CA, USA) was used as material for reversed phase chromatography. The HPLC program consisted of 17 varying steps with $200 \mathrm{~min}$ each, culminating in a total duration of $30 \mathrm{~h}$. The first 3 steps used a linear gradient of acetonitrile only (buffer B: $0.1 \%$ formic acid; buffer $\mathrm{A}: \mathrm{H}_{2} \mathrm{O}$ ) followed by 11 salt steps with the concentration increased $10 \%$ each for buffer C (250 mM ammonium acetate), with linear acetonitrile gradients in between. Three steps of high buffer D $(1.5 \mathrm{M} \mathrm{am}$ monium acetate) concentration followed at the end. The following parameters were used for the mass spectrometric analysis via LTQ Orbitrap velos (Thermo Fisher Scientific): ionization voltage of $1.8 \mathrm{kV}$; capillary temperature of $200^{\circ} \mathrm{C}$; tandem mass spectrometry fragmentations of the 20 most intense signals; dynamic mass exclusion of $60 \mathrm{~s}$; maximum orbitrap fill time of $500 \mathrm{~ms}$ in positive ion mode; maximum ion trap fill time of $100 \mathrm{~ms}$; and collision-induced dissociation at $35 \mathrm{~V}$. Collected data were filtered and examined by using MaxQuant software (21). The following parameters differ from the standard settings of
MaxQuant 1.5.2.8: decoy mode reward; minutes score for modified peptides 0 ; minutes $\delta$ score for modified peptides 0 ; and discard unmodified counterpart peptides false. In total, we analyzed 4 biological replicates with 3 technical replicates each. After peptide assignment using MaxQuant software as specified above, results from all 12 samples were compiled in 1 spreadsheet.

Peptides were crosschecked to exclude ambiguous protein assignments. In total, 17,956 peptide assignments were included in the analyses. The median of all peptide quantifications was 1.01. For additional analyses, we focused on subsets of peptides, specifically those with altered abundance upon treatment with AngII. To get a general impression, a liberal cutoff of phosphopeptide ratios of $>1.5$ or $<0.67$ for increase or decrease, respectively, was chosen [in parallel with Lefkowitz and colleagues (22)]. Of peptides, 15,242 had an AngII-to-vehicle ratio of $>0.67$ and $<1.5$. Four hundred sixty-five peptide ratios were $<0.67$, and 2249 were $>1.5$. Supplemental Table 1 gives a transparent overview of peptide abundance and quantification result.

\section{Functional analyses}

Functional annotation was performed with David Gene Ontology (https://david.ncifcrf.gov/summary.jsp and http://reactome.org) (23). These databases provide information about gene and protein attributes that are chiefly obtained by data mining and that enable the user to perform enrichment analyses. Phosphosite analyses were performed with PhosphoLogo (https://hpczwebapps.cit.nih.gov/ PhosphoLogo/) (24). Kinase substrates were analyzed in comparison with phosphosite analyses (http://wwww.phosphosite.org/) (25).

\section{Western blot}

Immunoblotting was carried out as described previously $(14,26)$. Antibodies for ERK, phospho-ERK1/2, GAPDH, phospho-p90 ribosomal S6 kinase (RSK) T359, and RSK1/2/ 3 were from Cell Signaling Technology (Danvers, MA, USA). Abs for actin, $\beta$-tubulin, FLAG, and FLAG (M2) were obtained from Sigma-Aldrich. Ab against LCP1 was obtained from Thermo Fisher Scientific. The generation of the $\mathrm{Ab}$ against phospho-LCP1 (Ser5) was described previously (27). All primary Abs with the exception of LCP1 (1:200) were used in a 1:1000 dilution.

Where indicated, cells were treated with AngII, ATP, losartan, and LPS (all from Sigma-Aldrich); Rp-8-Br-cAMP (Biolog, Bremen, Germany); U0126 (Cell Signaling Technology); BID1870 (Enzo Life Sciences, Lörrach, Germany); or GF109203 (Cayman Chemical, Ann Arbor, MI, USA).

\section{Quantification of Western blot signals}

Signals that were derived from the same immunoblot were densitometrically quantified by using Image (National Institutes of Health, Bethesda, MD, USA). Quotients from signals of phospho-specific Abs and from the complete amount of protein are shown. Evaluation was performed by using GraphPad Prism (GraphPad Software, La Jolla, CA, USA). All data show the SD of at least 3 independent experiments and were analyzed by using unpaired Student's $t$ test.

\section{Immunofluorescence}

Staining was performed as previously described (14). Abs against LCP1 (1:100) and Alexa Fluor 488 Phalloidin (1:200) were purchased from Thermo Fisher Scientific. Ab against T-plastin (1:50) 
was from GeneTex (Irvine, CA, USA). Samples were examined with an Axio Observer Z1 microscope and ApoTome technology (Carl Zeiss AG, Oberkochen, Germany; objective: EC Plan Neofluar $\times 40 / 1.30 *$ Oil DIC M27) using Axio Vision 4.7.

\section{Aggregation assay}

AB8 3F-AT1R cells were detached by using Accutase (SigmaAldrich) and diluted in aggregation buffer $(1.25 \mathrm{mM} \mathrm{CaCl}$, $10 \mathrm{mM}$ HEPES, $0.1 \%$ bovine serum albumin at physiologic osmolarity and $\mathrm{pH}$ ) to a density of $6 \times 10^{5}$ cells $/ \mathrm{ml}$. Cells were allowed to aggregate during shaking $\left(80 \mathrm{rpm}, 33^{\circ} \mathrm{C}\right)$ with or without the addition of $100 \mathrm{nM}$ AngII. Cell diameter, single cells, and cell aggregates of treated and control cells were calculated with the Luna Cell Counter (Logos Biosystems, Villeneuve $\mathrm{d}^{\prime}$ Ascq, France) after 0 and $30 \mathrm{~min}$ of incubation.

\section{Cloning of LCP and T-plastin mutants and transfection}

Human LCP1 cDNA was amplified from a human immortalized podocyte library (LCP1_fwd: 5'-CACCGGGCGCGCCATGGCCAGAGGATCA GTGTCCGATGAG-3', LCP1_rev: 5'-TTAATTAATCACACCCTCTTCATTCCTTTCCСC-3'), inserted into pENTR-D/TOPO vector and then cloned into the pmRFP-C2 vector [backbone manufacturer: R. Y. Tsien (28)], which allows the visualization of red fluorescent protein (RFP)-tagged LCP1 in fixed cells and in life cell experiments. Phosphorylation variants LCP1 S5A and LCP1 S5E were generated by using different forward primers during amplification, changing Ser5 into alanine (S5A: 5'-CACCGGGCGCGCCATGGCCAGAGGAGCAGTGTCCGATGAG-3') or changing Ser5 into glutamic acid (S5E: 5' CACCGGGCGCGCCATGGCCAGAGGAGAAGTGTCCGATGAG-3'). Deletion mutants were cloned with primers binding behind the LCP1 EF hand motifs, LCP1_minusEF (5'-CACCGGGCGCGCCGATGTTGCCAAGACCTTTAGAAAAGC-3'), amplifying AA 85-628, or LCP1_phospho_minusEF (5' CACCGGGCGCGCCATGGCCAGAGGATCAGTGTCCGATGAGGAAATGATGGAGCTCAGAGATGTTGCCAAGACCTTTAGAAAAGC-3'), amplifying AA 1-15 + 85-628. Human T-plastin cDNA was also amplified from the human immortalized podocyte library by using the primers WT_fwd (5'CACCGGGCGCGCCATGGATGAGATGGCTACCACTCAGATT-3') and WT_rev (5'-TTAATTAATTACACTCTCTTCATTCCCCTGCC-3'). For amplification of the deletion mutant, T-plastin_minusEF, the forward primer was replaced with the primer minusEF-fwd (5'-CACCGGGCGCGCCATTGCCAAGACCTTCCGCAAAGCAATCAACAGG-3'). Amplified DNA was also cloned into the pmRFP-C2 vector. Transient transfection of podocytes was performed by using Lipofectamine 2000 (Thermo Fisher Scientific) according to the manufacturer's instructions.

\section{Quantification of filopodia length and amount}

RFP signals in immunofluorescence images of cells transfected with pRFP-LCP1-WT (wild-type), pRFP-LCP1-S5A, pRFP-LCP1S5E, and pEGFP-C2 empty vector (mock) were analyzed by using the filopodia code in MatLab (MathWorks, Natick, MA, USA) as described in detail by Nilufar et al. (29). The number of filopodia per cell and the average length of filopodia in transfected cells were calculated.

\section{Live cell imaging}

For live cell imaging, AB8 3F-AT1R podocytes were seeded on an Ibidi $\mu$-Dish 35-mm high with glass bottom (Ibidi, Martinsried,
Germany) and transiently transfected with the different pmRFPLCP1 or pmRFP-T-plastin constructs. Using the microscope mentioned above, approximately 40 time-lapse images of transfected cells $48 \mathrm{~h}$ after transfection were taken every $20 \mathrm{~s}$, starting with stimulation with $100 \mathrm{nM}$ AngII directly under the microscope after the fifth image (video time, $13 \mathrm{~min}$ ). An additional end point photo was obtained $15 \mathrm{~min}$ after stimulation. For blockade of AT1R, transfected cells were preincubated for $2 \mathrm{~h}$ with losartan $(10 \mu \mathrm{M})$ or for inhibition of RSK with BID-1870 $(10 \mu \mathrm{M})$ for $3 \mathrm{~h}$ before the start of experiments. For $\mathrm{Ca}^{2+}$-reduced conditions, cells were incubated with BAPTA-AM $(10 \mu \mathrm{M}, 1 \mathrm{~h}$; AAT Bioquest, Sunnyvale, CA, USA) to complex intracellular $\mathrm{Ca}^{2+}$ ions. Furthermore, extracellular calcium concentration was reduced to $0.8 \mathrm{mM}$ by adding an adequate amount of $\mathrm{Ca}^{2+}$-free KrebsRinger solution $\left(145 \mathrm{mM} \mathrm{NaCl}, 1.6 \mathrm{mM} \mathrm{K} \mathrm{HPO}_{4}, 0.4 \mathrm{mM}\right.$ $\mathrm{KH}_{2} \mathrm{PO}_{4}, 5 \mathrm{mM}$ glucose, $1 \mathrm{mM} \mathrm{MgCl}, 5 \mathrm{mM}$ EGTA).

\section{RESULTS}

\section{Angll leads to quantitative changes in the phosphoproteome of human podocytes}

We chose an immortalized human podocyte cell line (AB8/13) with robust expression of FLAG-tagged AT1R (AB8 3F-AT1R) as a model system (14). These cells resemble podocytes in vivo with regard to their expression of podocyte-specific cytoskeletal proteins, nephrin and synaptopodin (30). Moreover, they can form filopodia and lamellipodia and, as a result of their large size, they are excellent targets for the visualization of intracellular processes.

Temporal dynamics of phosphorylation events upon GPCR activation are highly complex (31-33); therefore, we performed time course experiments and demonstrated the phosphorylation of ERK within the first $15 \mathrm{~min}$ after AngII stimulation (14). Thus, we chose this time point for our proteomic study.

Relative quantification of AngII-dependent changes of the cellular phosphoproteome was performed by using SILAC coupled with phosphopeptide enrichment and liquid chromatography-tandem mass spectrometry (Supplemental Fig. 1A). Accordingly, AB83F-AT1R cells that were grown in SILAC culture media were treated with AngII (100 $\mathrm{nM})$ or vehicle for $15 \mathrm{~min}$. An effective AngII stimulation was demonstrated by increased ERK phosphorylation in a Western Blot (Supplemental Fig. 1B). Subsequently, cell extracts were used for sample preparation, including phosphopeptide enrichment, mass spectrometry, bioinformatic peptide assignment, and semiquantitative quantification. With this approach, we identified 17,956 peptides in 4 biological replicates, each performed in 3 technical replicates. A total of 4951, 4729, 5173, and 3103 phosphopeptides was found, corresponding to 1494, 1209, 1224, and 891 phosphoproteins-in replicates 1, 2, 3, and 4, respectively (Fig. 1 and Supplemental Fig. 1C). After removal of redundant peptides, 6323 unique phosphopeptides could be traced back to 2081 distinct proteins. A large proportion of 1326 proteins were found in at least 2 of the experiments (Fig. 1A). We observed increased and decreased amounts of phosphopeptides upon $15 \mathrm{~min}$ of treatment with AngII (Fig. 1B). Among the identified phosphorylation sites, $\sim 90 \%$ were 

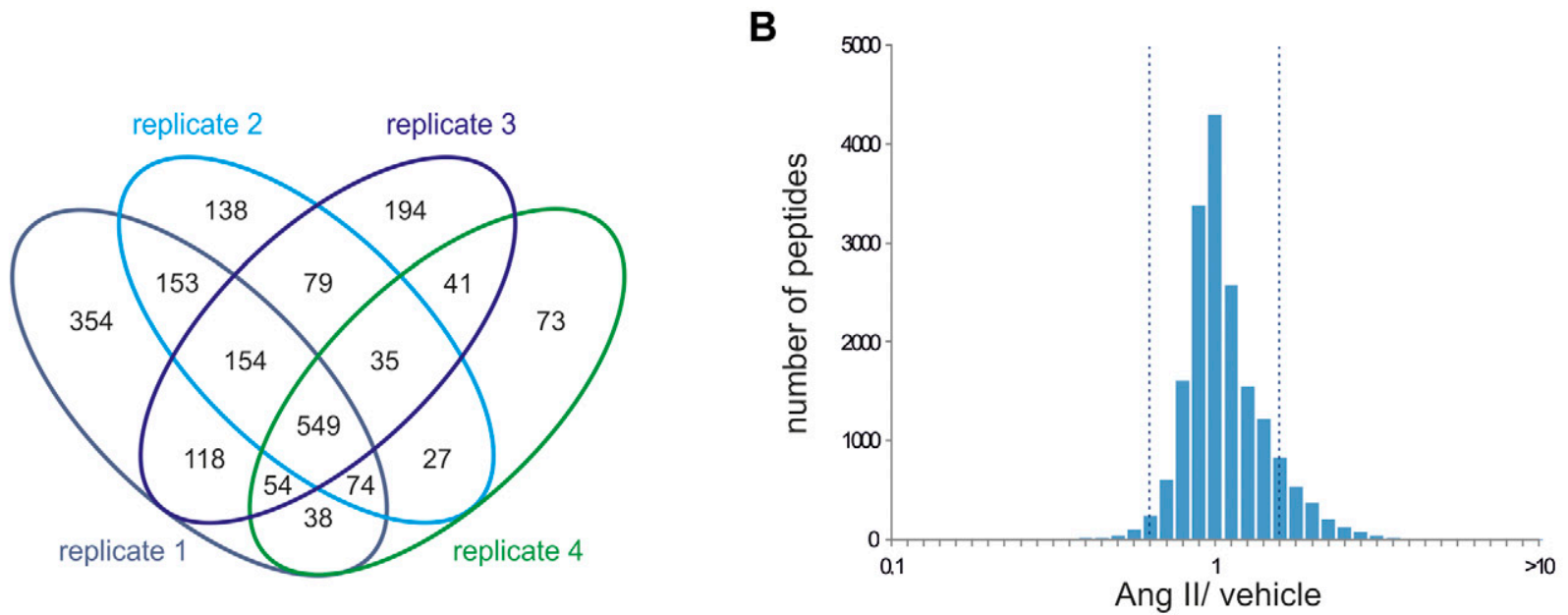

II/ vehicle
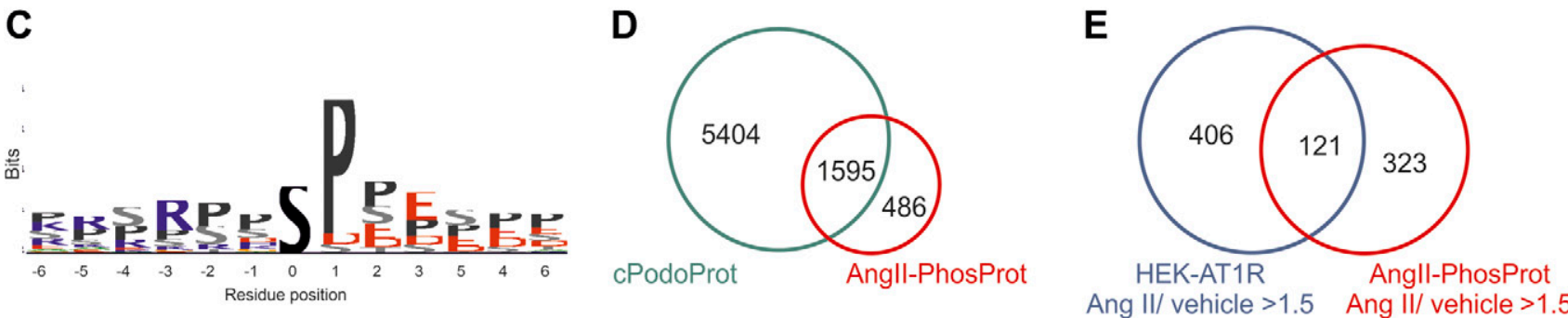

Figure 1. Characterization and quantitation of AngII-induced regulation of the phosphoproteome in human immortalized podocytes. A) Venn diagram of the 2081 unique protein assignments in 4 biological replicates of AB8 3F-AT1R cells. A total of 1494, 1209, 1224, and 891 phosphoproteins were found in replicates 1, 2, 3, and 4, respectively. B) Histogram of the distribution of peptide ratios comparing podocytes that were treated with AngII (100 nM; $15 \mathrm{~min})$ vs. vehicle. For additional analyses, a liberal cutoff of phosphopeptide ratios of $>1.5$ or $<0.67$ for increase or decrease, respectively, was chosen. $C$ ) Analysis of the phosphorylation site sequence motif, depicted for all peptides with a $>1.5$ AngII-to-vehicle ratio was performed with PhosphoLogo. D) Venn diagram of all proteins identified in this study (AngII-PhosProt) compared with a non-phospho-enriched proteome characterization of primary murine podocytes (cPodoProt) from Rinschen et al. (33). E) Venn diagram comparing the phosphoproteins that were increased in this study (AngII-PhosProt) compared with phosphoproteins that were increased in a study of AT1R signaling in HEK293 cells (HEK-AT1R) from Christensen et al. (34).

phosphoserine, $\sim 9 \%$ phosphothreonine, and $\sim 1 \%$ phosphotyrosine. Phosphosite analysis demonstrated that treatment of podocytes with AngII for 15 min led to an increased serine/threonine phosphorylation at prolinedirected sites (proline at position +1 ), which fits to a motif that is predominantly used in MAPK signaling (Fig. 1C). This sequence motif preference was reproducible for both $>1.5 \times$ and $>3 \times$ increased AngII/vehicle phosphopeptide ratios. We next compared our data with other studies in this field. A large proportion of the proteins that we identified in our samples have been repeatedly found in other renal phosphoproteomic databases, but, in addition, we could identify several novel phospho-targets of AT1R signaling in podocytes. In comparison to other studies, it is interesting to overlap the phosphoproteins identified in the podocyte cell line in our study with native glomerular podocytes, and to evaluate parallels with studies that characterized AngII-induced phosphoproteomic changes in different cell types. Of proteins, 1595 from our screen have previously been proven to be expressed in podocytes by a non-phospho-enriched proteome characterization of primary cultured murine podocytes (34) (Fig. $1 D$ ). In another study, the relative quantification of the AngII-dependent phosphoproteome of AT1R-expressing
HEK293 cells was performed (35). One hundred twentyone of the phosphoproteins that were increased in our study were also regulated in HEK293 cells (35), whereas 323 proteins were apparently podocyte-specific targets of AngII phospho-signaling (Fig. 1E).

\section{Angll increased phosphorylation of actin filament-associated peptides}

To get a general impression, a liberal cutoff of phosphopeptide ratios of $>1.5$ or $<0.67$ for increase or decrease, respectively, was chosen [in parallel to Lefkowitz and colleagues (22) and Christensen et al. (35)].

With these criteria, $85 \%$ of the total 17,956 peptides had an AngII-to-vehicle ratio of $>0.67$ and $<1.5$, which was resumed as unregulated, in $2.5 \%$ the peptide ratio was decreased $(<0.67)$ and in $12.5 \%$ the ratio was increased $(>1.5)$. Four hundred twenty-six unique phosphorylation sites were increased, 1560 were unchanged, and 41 were decreased. Supplemental Table 1 provides an overview of all peptide abundances and a quantification of results. Phosphopeptides with the largest relative increase in abundance belonged to the proteins tenascin, integrin- $\beta 6$, 
neuroblast differentiation-associated protein, LCP1, optineurin, plasminogen activator inhibitor 1 , serine/threonine protein kinase D2, protein bicaudal C homolog 1, phalladin, and ephrin type-A receptor 2 . Table 1 summarizes the 10 phosphopeptides with the largest increase in abundance.

Quantitative changes in protein phosphorylation often reflect the activation of distinct cellular signaling processes. Indeed, most of the increased phosphopeptides from our screen were part of signal transduction pathways (Fig. $2 A)$. Next, gene ontology analyses and functional classifications were used to screen our phosphoproteomic results and to classify the regulated phosphopeptides-we used the Database for Annotation, Visualization, and Integrated Discovery (DAVID) Gene Ontology database (http://david.abcc.ncifcrf.gov). This approach revealed that phosphopeptides that were related to actin filaments, lamellipodia, and cell leading edge were over-represented among the increasingly phosphorylated peptides (Fig. 2B). Furthermore, phosphorylation of proteins that influence molecular functions, such as intramolecular transferase activity and Rho GTPase activator activity, was increased after AngII stimulation (Fig. 2C). With regard to signaling pathways and biological processes, mammalian target of rapamycin signaling, glucose metabolism, and focal adhesion were over-represented (Supplemental Fig. 2A, $B$ ).

On the basis of the over-representation of actin-associated pathways in our analyses and the great importance of actin cytoskeletal dynamics for podocytes, we took a closer look at this group of proteins and identified many phosphopeptides from proteins that were linked with the actin cytoskeleton (Table 2). A schematic overview of phosphoproteins related to the gene ontology terms, actin filaments, lamellipodia, and cell leading edge is given in Fig. $2 D$.

\section{Angll-induced LCP1 phosphorylation is mediated by the kinases RSK, PKA, and PKC}

Phospho-Ser5 LCP1 was one of the most enriched peptides in our phosphoproteomic screen after $15 \mathrm{~min}$ of AngII treatment in human podocytes (Table 1). The protein LCP1 is one of 3 plastin isoforms that are found in mammalian cells that belong to the $\alpha$-actinin family of actin cross-linking proteins, which play a crucial role in podocyte biology. Indeed, mutations in the protein $\alpha$-actinin-4, for example, have previously been linked to podocyte injury (36). In contrast to other $\alpha$-actinin family members, plastins have 2 actin-binding domains in a single polypeptide chain. Cross-linking parallel actin filaments into tight bundles, plastins can stabilize larger-order F-actin structures. On the one hand, the bundling activity of LCP1 is regulated by calcium binding at EF-hand loops and, on the other, by serine phosphorylation sites, both of which are included in the N-terminal region of LCP1 (13).

First, AngII-induced phosphorylation of LCP1 at Ser5 (p-LCP1) was replicated in Western blot experiments with a highly specific $\mathrm{Ab}$ against this phosphorylation site (27). Total LCP1 abundance remained unchanged (Supplemental Fig. 3). AngII-dependent phosphorylation of ERK at the activating Thr202/Tyr204 site (p-ERK) served as control for stimulation, and the stable expression of 3FAT1R served as control of the cell line. Evaluation of 4 independent experiments allowed quantification of the AngII-dependent increase of LCP1 and ERK phosphorylation, shown as a ratio of phosphorylated proteins and the total amount of proteins (Supplemental Fig. 3).

It is known that the extracellular stimulation of AT1R with AngII increases the level of intracellular calcium and, in part as a consequence, leads to the activation of several kinases, which transfers additional signal transduction $(10,11)$. In additional experiments, we examined the signaling pathway of AngII-induced LCP1 phosphorylation. To investigate whether an AngII-induced $\mathrm{Ca}^{2+}$ influx is primarily responsible for LCP1 phosphorylation, we treated cells with ionomycin, which elicits a large $\mathrm{Ca}^{2+}$ increase in the cytoplasm of cells (37); however, an increase in intracellular $\mathrm{Ca}^{2+}$ alone did not lead to an increase in p-LCP1 (Fig. $3 A$ ). Treatment with a high concentration of ATP, which, similar to AngII, leads to a $G$ protein-induced increase of intracellular $\mathrm{Ca}^{2+}$, could, in contrast, induce the phosphorylation of LCP1 and that of kinases ERK and RSK (p-RSK). LPS is known as a podocyte-affecting substance, which leads in vivo to foot process effacement and damage to the slit diaphragm (38). To examine whether podocyte damage in general leads to LCP1

TABLE 1. Compilation of the 10 peptides with the largest increase in peptide ratio upon AngII stimulation (100 nM; 15 min) vs. control

\begin{tabular}{|c|c|c|c|c|}
\hline Protein name & Gene symbol & Mean Ang/Ktr & Sequence & Modification site \\
\hline Tenascin-N & $\mathrm{TNN}$ & 29.45 & Y*VVRY*T*SAGGETR & Y650, Y654; T655 \\
\hline Integrin- $\beta 6$ & ITGB6 & 13.22 & VGDT*AS*FSVT*VNIPHCER & $\mathrm{T} 414 ; \mathrm{S} 416 ; \mathrm{T} 420$ \\
\hline $\begin{array}{l}\text { Neuroblast differentiation-associated } \\
\text { protein AHNAK }\end{array}$ & AHNAK & 8.09 & LKS*EDGVEGDLGETQSR & S135 \\
\hline L-Plastin & LCP1 & 7.09 & GS*VSDEEMMELR & S5 \\
\hline Optineurin & OPTN & 5.40 & HGARTS*DSDQQAYLVQR & S520 \\
\hline \multirow[t]{2}{*}{$\begin{array}{l}\text { Plasminogen activator inhibitor } 1 \\
\text { RNA-binding protein }\end{array}$} & SERBP1 & 5.38 & S*KSEEAHAEDSVMDHHFR & S313 \\
\hline & & 5.26 & S*KS*EEAHAEDSVMDHHFR & S313; S315 \\
\hline Serine/threonine-protein kinase D2 & PRKD2 & 4.25 & RLS*STSLAS*GHSVR & S197; S203 \\
\hline Protein bicaudal C homolog 1 & BICC1 & 4.21 & S*PSHSGNAGDLK & S633 \\
\hline Palladin & PALLD & 4.17 & IAS*DEEIQGTK & S669 \\
\hline Ephrin type-A receptor 2 & EPHA2 & 4.08 & LPS*TSGSEGVPFR & S897 \\
\hline
\end{tabular}




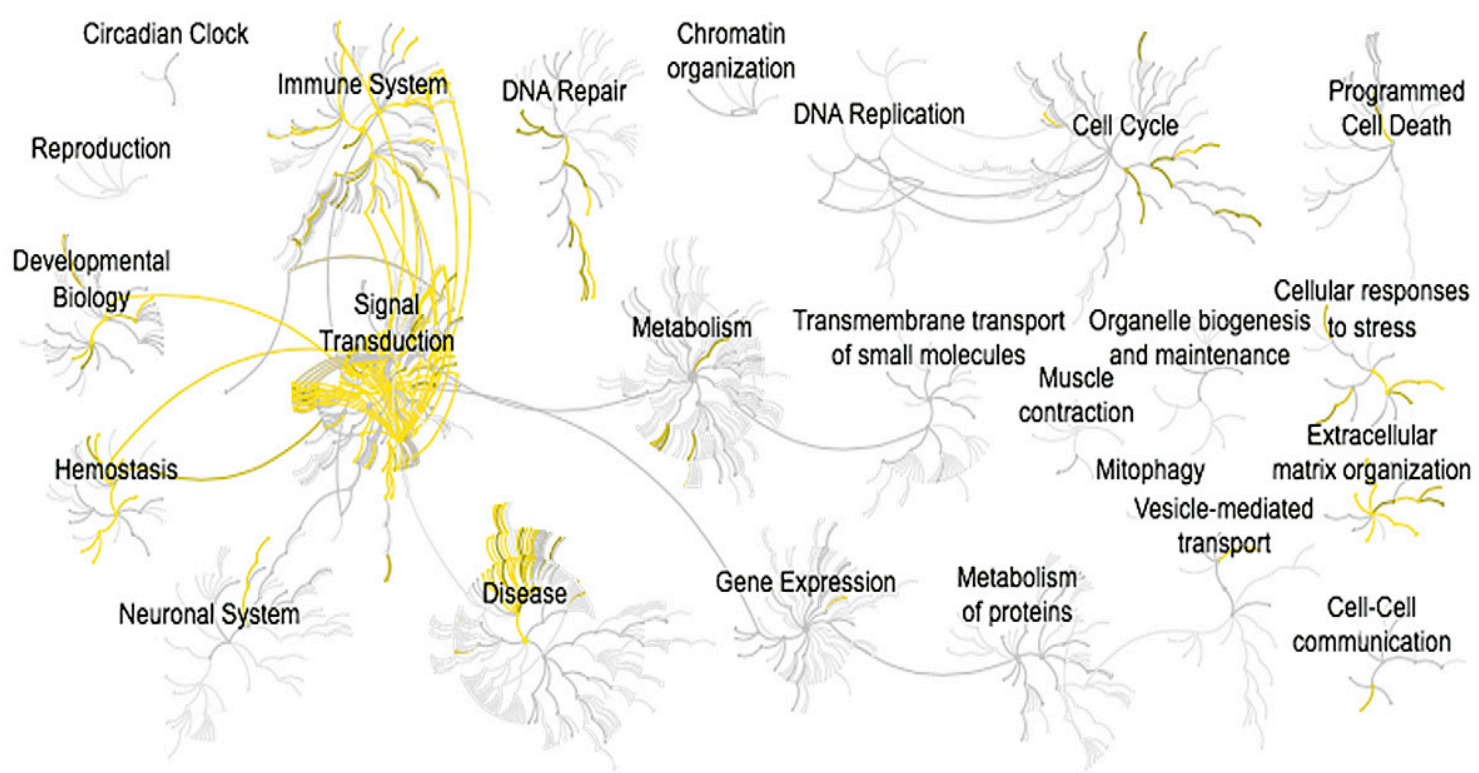

B

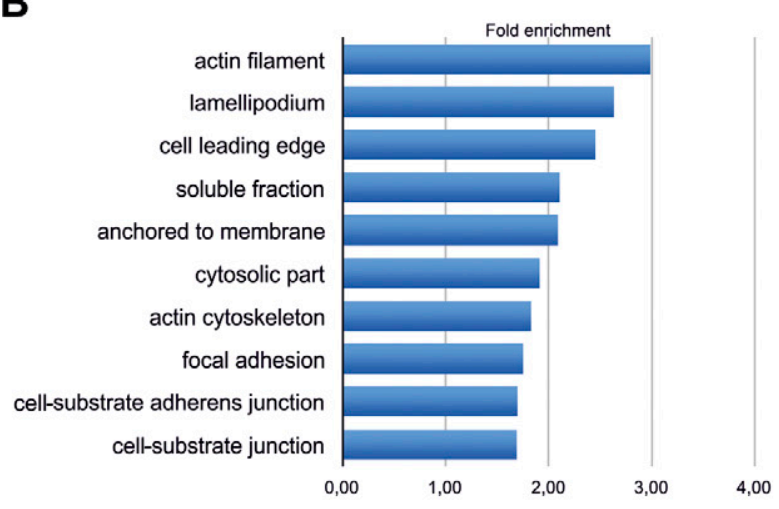

C intramolecular transferase activity,.. Rho GTPase activator activity actin binding

Ras GTPase activator activity protein serine/threonine kinase activity GTPase binding protein kinase binding protein kinase activity cytoskeletal protein binding protein complex binding
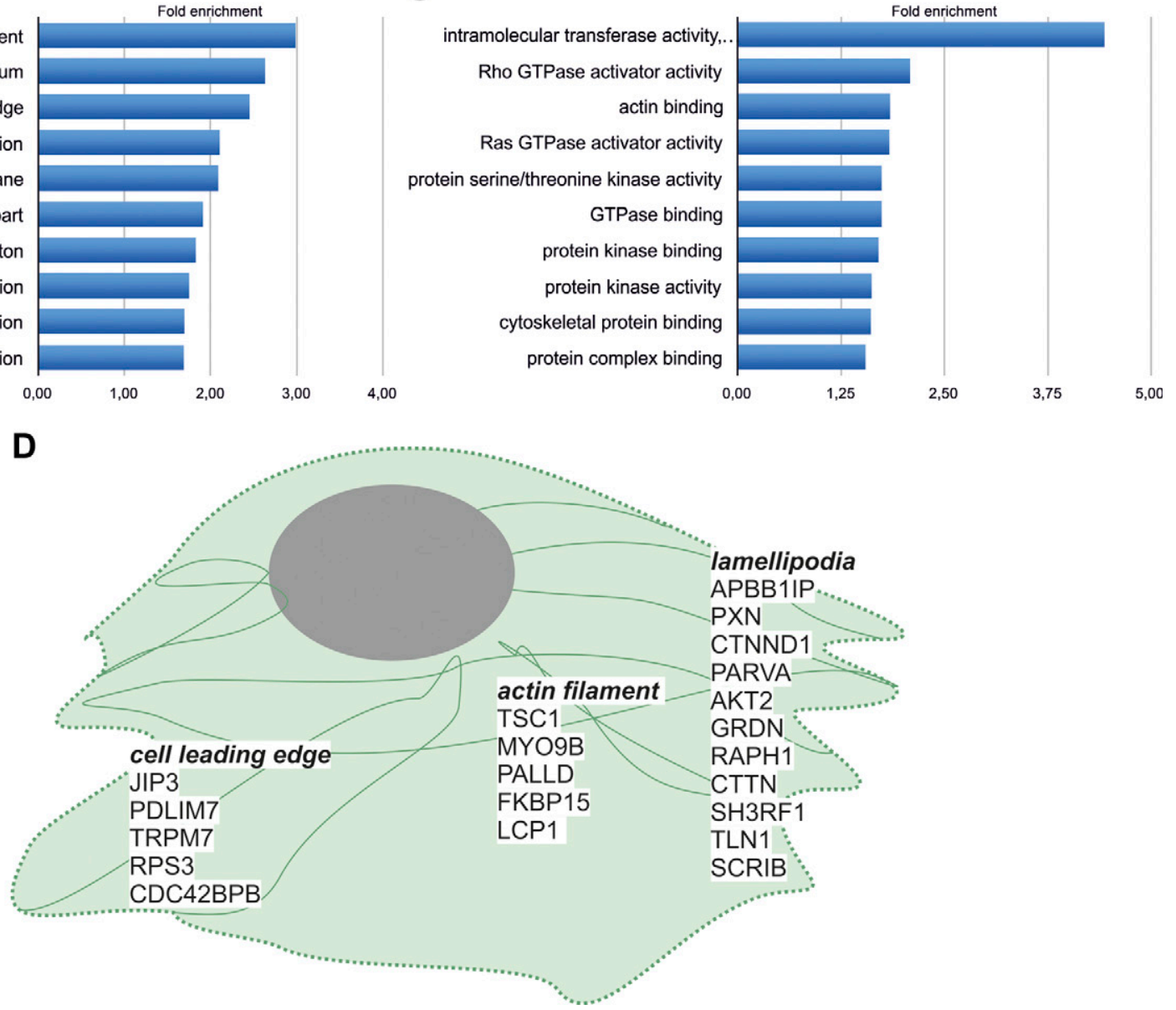

Figure 2. Signaling pathways over-represented among regulated phosphoproteins. A) Analysis demonstrates that proteins involved in signal transduction are predominant among increased phosphopeptides. $B$ ) A gene ontology functional classification regarding cellular components revealed that phosphopeptides related to actin filaments, lamellipodia, and cell leading edge were over-represented among increased phosphopeptides. C) A gene ontology functional classification revealed that phosphopeptides related to molecular functions, such as intramolecular transferase activity and Rho GTPase activator activity, were increased after AngII stimulation. D) Schematic representation of increased phosphoproteins associated with cellular components cell leading edge, actin filament, and lamellipodia, as defined by gene ontology terms. 
TABLE 2. List of all actin-associated proteins from the study

\begin{tabular}{|c|c|c|c|}
\hline Gene symbol & $\begin{array}{l}\text { Median, all } \\
\text { peptides }\end{array}$ & $\begin{array}{l}\text { Peptide } \\
\text { minimum }\end{array}$ & $\begin{array}{c}\text { Peptide } \\
\text { maximum }\end{array}$ \\
\hline LCP1 & 4.01 & 0.92 & 7.09 \\
\hline PALLD & 2.15 & 1.09 & 4.17 \\
\hline PHACTR4 & 1.26 & 0.47 & 3.62 \\
\hline MYLK & 1.3 & 1.03 & 3.19 \\
\hline FKBP15 & 1.46 & 0.85 & 3.03 \\
\hline PLEC & 0.98 & 0.56 & 2.99 \\
\hline MARCKS & 1.22 & 0.74 & 2.26 \\
\hline VCL & 1.62 & 1.43 & 2.15 \\
\hline FLNA & 1.34 & 0.93 & 2.04 \\
\hline SNTB2 & 1.23 & 1.04 & 2.03 \\
\hline TNS1 & 1.42 & 0.78 & 1.97 \\
\hline PARVA & 1.97 & 1.97 & 1.97 \\
\hline CYTSA & 1.61 & 0.98 & 1.92 \\
\hline SSH2 & 1.61 & 1.09 & 1.88 \\
\hline MPRIP & 1.03 & 0.81 & 1.87 \\
\hline LASP1 & 1.85 & 1.85 & 1.85 \\
\hline MN2 & 1.55 & 1.03 & 1.81 \\
\hline EHBP1 & 1.29 & 1.1 & 1.74 \\
\hline ADD1 & 1.25 & 1.06 & 1.7 \\
\hline FLNC & 1.34 & 1.18 & 1.68 \\
\hline INF2 & 1.18 & 0.9 & 1.68 \\
\hline ARHGEF7 & 1.65 & 1.64 & 1.67 \\
\hline SPTBN1 & 1.06 & 0.42 & 1.63 \\
\hline MYO9B & 1.36 & 0.99 & 1.61 \\
\hline FLNB & 1.4 & 0.64 & 1.57 \\
\hline SPIRE1 & 1.56 & 1.56 & 1.56 \\
\hline BAIAP2L1 & 1.05 & 0.91 & 1.55 \\
\hline CAP1 & 1.35 & 1.08 & 1.54 \\
\hline CFL1 & 1.44 & 1.27 & 1.49 \\
\hline ANLN & 1.29 & 1.21 & 1.49 \\
\hline EMD & 1.48 & 1.48 & 1.48 \\
\hline SMTN & 1.27 & 1.2 & 1.47 \\
\hline ACTN1 & 1.43 & 1.43 & 1.43 \\
\hline EPB41L1 & 0.99 & 0.79 & 1.41 \\
\hline MYH9 & 1.36 & 0.95 & 1.39 \\
\hline ADD3 & 1.22 & 0.96 & 1.38 \\
\hline PHACTR2 & 1.37 & 1.37 & 1.37 \\
\hline SNTA1 & 1.36 & 1.36 & 1.36 \\
\hline LIMA1 & 1.02 & 0.92 & 1.36 \\
\hline FLII & 1.34 & 1.34 & 1.34 \\
\hline NAV2 & 1.14 & 0.81 & 1.3 \\
\hline LQGAP3 & 1.29 & 1.29 & 1.29 \\
\hline ANXA2 & 1.13 & 1 & 1.29 \\
\hline MACF1 & 1.13 & 1.08 & 1.29 \\
\hline DIAPH1 & 1.26 & 1.26 & 1.26 \\
\hline FMNL1 & 1.24 & 1.24 & 1.24 \\
\hline DIAPH3 & 1.22 & 1.22 & 1.22 \\
\hline EHBP & 0.98 & 0.76 & 1.21 \\
\hline DST & 0.88 & 0.78 & 1.19 \\
\hline ARPC5L & 1.17 & 1.17 & 1.17 \\
\hline DBN1 & 1.08 & 0.89 & 1.17 \\
\hline ARHGEF6 & 1.15 & 1.15 & 1.15 \\
\hline AFAP1 & 1.06 & 1.03 & 1.14 \\
\hline EPB41L2 & 1.09 & 0.97 & 1.13 \\
\hline MYH10 & 1.13 & 1.13 & 1.13 \\
\hline LMO7 & 0.99 & 0.89 & 1.11 \\
\hline CYTSB & 0.99 & 0.92 & 1.1 \\
\hline LIMCH1 & 1.05 & 0.89 & 1.09 \\
\hline CLMN & 1.08 & 1.08 & 1.08 \\
\hline CALD1 & 1.07 & 1.07 & 1.07 \\
\hline EPB41L3 & 0.99 & 0.86 & 1.06 \\
\hline MICAL3 & 1.05 & 1.05 & $\begin{array}{c}1.06 \\
\text { (continued) }\end{array}$ \\
\hline
\end{tabular}

TABLE 2. (continued)

\begin{tabular}{lccc}
\hline \hline Gene symbol & $\begin{array}{c}\text { Median, all } \\
\text { peptides }\end{array}$ & $\begin{array}{c}\text { Peptide } \\
\text { minimum }\end{array}$ & $\begin{array}{c}\text { Peptide } \\
\text { maximum }\end{array}$ \\
\hline SYNE2 & 1.04 & 1.04 & 1.04 \\
SPTAN1 & 1.03 & 1.03 & 1.03 \\
SNTB1 & 1.01 & 0.99 & 1.03 \\
ACTN4 & 1.03 & 1.03 & 1.03 \\
MAPRE2 & 0.97 & 0.85 & 1.01 \\
PPP1R9A & 1.01 & 1.01 & 1.01 \\
NEXN & 0.98 & 0.95 & 1.01 \\
SVIL & 0.96 & 0.86 & 1.01 \\
LRCH3 & 1 & 1 & 1 \\
TMOD3 & 1 & 1 & 1 \\
MICALL1 & 0.75 & 0.6 & 0.98 \\
MICAL2 & 0.96 & 0.96 & 0.96 \\
UTRN & 0.96 & 0.96 & 0.96 \\
SYNE1 & 0.89 & 0.89 & 0.89 \\
MICAL1 & 0.8 & 0.74 & 0.87 \\
LRCH1 & 0.8 & 0.8 & 0.8 \\
SYNPO & 0.8 & 0.8 & 0.8 \\
SHROOM3 & 0.79 & 0.79 & 0.79 \\
SYNPO2 & 0.76 & 0.75 & 0.76 \\
WASF2 & 0.74 & 0.73 & 0.74 \\
ABLIM1 & 0.65 & 0.65 & 0.65 \\
\hline & & &
\end{tabular}

phosphorylation, cells were treated with LPS, which resulted in a slight increase in phosphorylation.

AngII treatment, in addition to the activation of ERK and phosphorylation of LCP1 already shown in Supplemental Fig. 3, led to increased phosphorylation of RSK at Thr359. This phosphorylation of RSK and of ERK and LCP1 could be reduced by preincubation with the AT1R blocker losartan.

It has been demonstrated in breast cancer cell lines that ERK, RSK, PKA, and PKC are involved in the regulation of LCP1 phosphorylation at Ser5 $(27,39,40)$; therefore, we investigated whether these kinases are also responsible for LCP1 phosphorylation in podocytes. Treatment with the specific RSK inhibitor, BID1870 (41), or the ERK inhibitor, U0126 (42), completely blocked AngII-induced LCP1 phosphorylation, which demonstrated that ERK and RSK are involved in LCP1 phosphorylation also in podocytes. The inhibitor, U0126, is an indirect ERK inhibitor and prevented AngII-induced ERK phosphorylation (Fig. 3A) via inhibition of the kinase MEK1/2, which usually phosphorylates and activates ERK (42). In contrast, the RSK inhibitor used in this study directly inhibited RSK kinase activity without influencing AngII-induced phosphorylation of RSK (Fig. 3A) (41).

In addition to phosphorylation via ERK and RSK, the PKA-mediated phosphorylation of LCP1-previously shown in breast cancer cells (39) - could be confirmed in podocytes. Preincubation with the PKA-specific inhibitor, RP-8-Br-cAMP (43), diminished LCP1 phosphorylation, whereas RSK phosphorylation was preserved after treatment (Fig. 3B). This result suggests that LCP1 Ser5 is not exclusively phosphorylated by RSK but also in parallel by PKA.

Similarly, inhibition of PKC with the pan-PKC inhibitor, GF109203X (44), blocked AngII-induced LCP1 phosphorylation (Fig. 3C). It also influenced RSK phosphorylation 
A

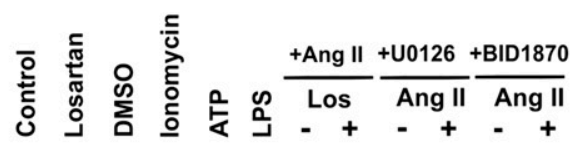
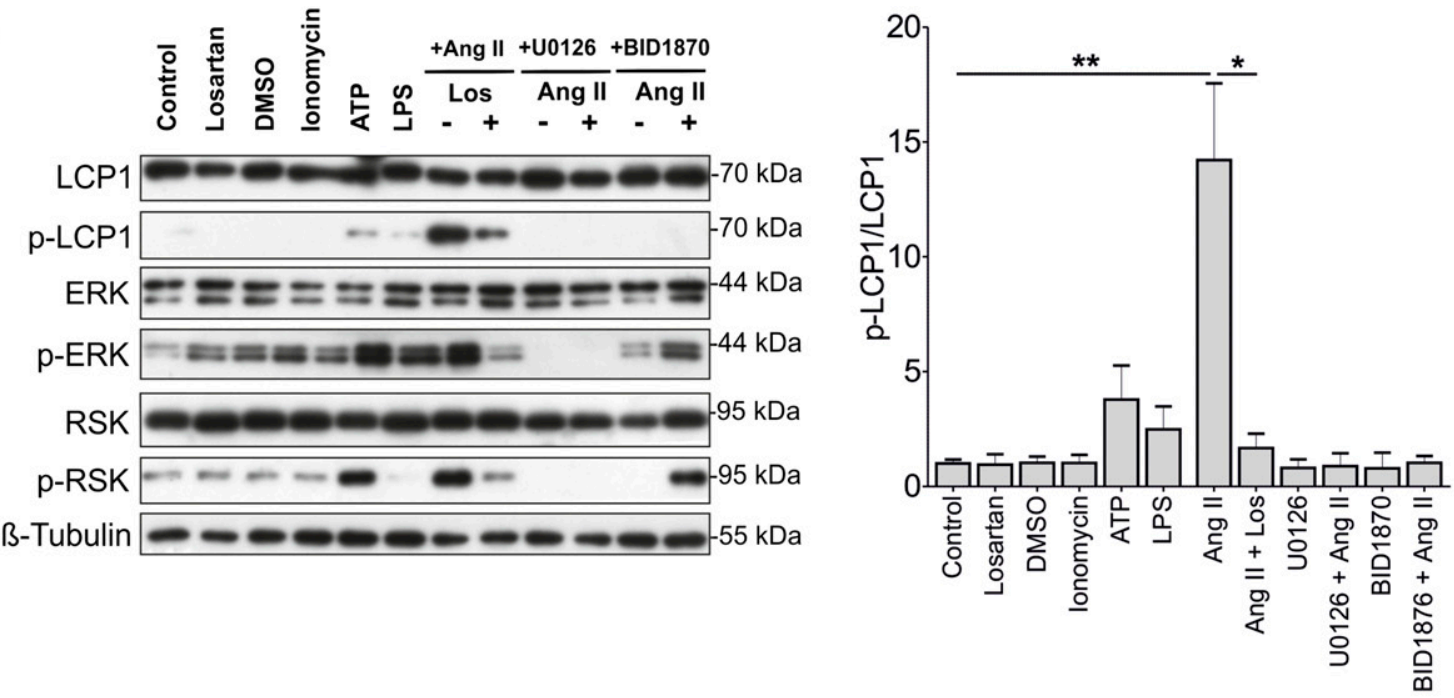

B

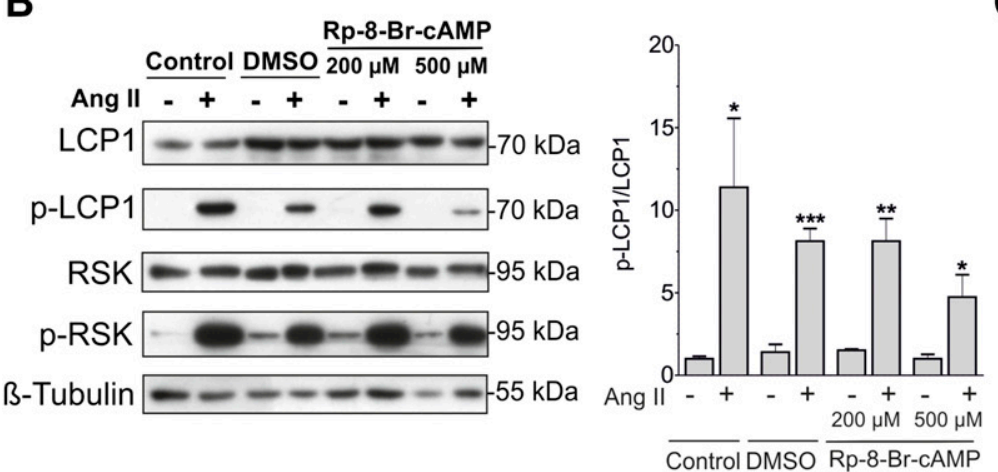

C
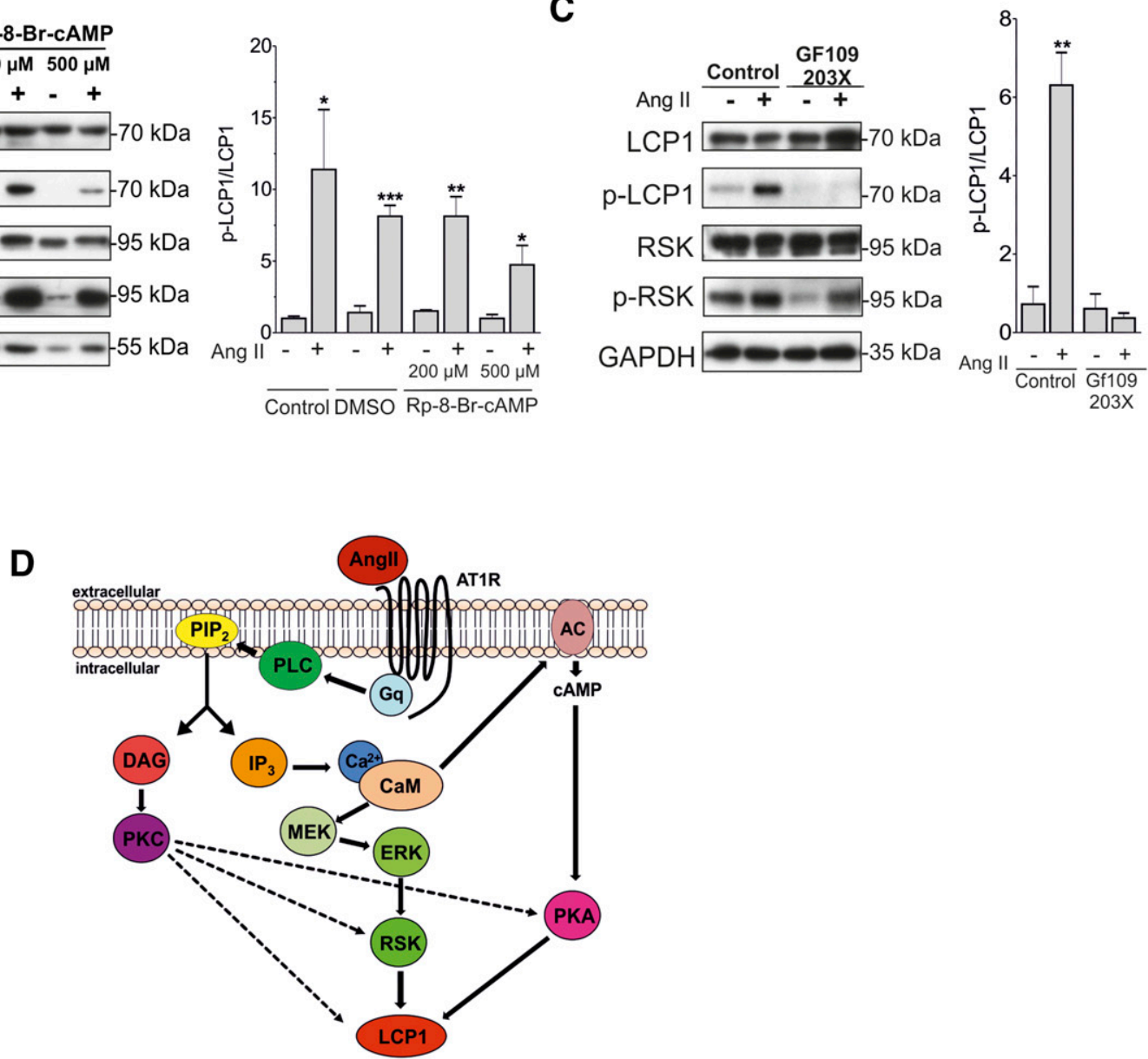

Figure 3. Phosphorylation of LCP1 is AngII dependent and can occur via ERK, RSK, PKA, and PKC kinases. For a more precise examination of AngII-dependent signaling events that result in LCP1 phosphorylation, different kinase inhibitors were used. In addition, the induction of LCP1 phosphorylation by general calcium increase (ATP, ionomycin) or podocyte damage (LPS) was tested. A) Representative Western blot results from podocytes that were treated with AngII (100 nM, 15 min), ionomycin (500 $\mathrm{nM}, 5 \mathrm{~min})$, ATP $(1 \mu \mathrm{M}, 5 \mathrm{~min})$, or LPS $(1 \mathrm{mM}, 24 \mathrm{~h})$ (left). Where indicated, cells were preincubated with AT1R blocker (Los; $10 \mu \mathrm{M}, 2 \mathrm{~h})$, RSK inhibitor BID1870 (10 $\mathrm{M}, 4 \mathrm{~h})$, or ERK inhibitor U0126 (10 $\mu \mathrm{M}, 2 \mathrm{~h})$. Ratio between phosphorylated and total amount of LCP1 from 4 independent experiments (right). B) Representative Western blot from podocytes that were treated with AngII (100 nM, 15 min) (left). Preincubation with PKA-specific inhibitor RP-8-Br-cAMP in higher concentration diminishes AngIIinduced LCP1 phosphorylation. Ratio between phosphorylated and total amount of LCP1 from 4 independent experiments (right). C) Representative Western blot results from podocytes that were treated with AngII (100 nM, 15 min) (left). Preincubation with the 
as treatment with GF109203X reduced the p-RSK signal; however, treatment with AngII still activates RSK (phosphorylation of RSK), which indicated an RSK-independent contribution of PKC to LCP1 phosphorylation.

In summary, our data indicate that AngII-induced LCP1 phosphorylation in podocytes can occur in parallel via activation of ERK and subsequently RSK or via an AngII-induced PKA activation or via PKC activation, directly or indirectly via RSK or PKA (Fig. 3D).

\section{Intracellular localization of LCP1 changes after Angll stimulation}

Immunofluorescent staining of endogenous LCP1 in podocytes demonstrated that LCP1 colocalized, in part, with actin, particularly in needle-like cell-cell contacts (Fig. 4A, top). LCP1 staining in such extensions was observed in a previous study and the structures were identified as filopodia (45). Indeed, we also observed LCP1 and actin-stained filopodia forming cell-cell contacts in podocytes. During AngII treatment, LCP1 and actin redistributed to cell borders (Fig. $4 A$, bottom). Furthermore, the morphology of cell-cell contact sites changed: the number of needle-like structures seemed to decrease after AngII stimulation and, instead, cell contact sites seemed to be broadened, in parts overlapping. This observation was confirmed in experiments with cells that were grown to confluence. These cells were too dense to visualize filopodia but AngII stimulation induced membrane ruffling; cells seemed to enlarge and grow out of the cell assembly, forming lamellipodia (Fig. 4B). To quantify the effect of membrane ruffling, we counted the cells with ruffled membranes with or without AngII treatment and confirmed that nearly all cells reacted to AngII stimulation with membrane ruffling (Fig. 4C).

As such actin-based changes at the plasma membrane as filopodia or lamellipodia formation are often initial steps for cell-cell contact formation, we applied a cell aggregation assay to investigate whether AngII stimulation influences cell-cell aggregation of podocytes. For this assay, cells were cultured in suspension with and without AngII. Indeed, our experiments revealed significantly increased AngII-dependent cell clustering (Fig. 4D), which fits to previous observations made by Janji et al. (27) that showed that LCP1 phosphorylation influences the cell-cell contact formation in HEK293T cells.

\section{LCP1 phosphorylation influences cell-cell contacts and filopodia formation}

It has been previously shown that phosphorylation of LCP1 at Ser5 promotes the targeting of LCP1 to actin assembly sites $(27,40)$. To address this, we visualized endogenously phosphorylated LCP1 (p-Ser5-LCP1) in podocytes. Staining with a highly specific $\mathrm{Ab}$ (27) demonstrated that p-Ser5-LCP1 was predominantly localized at the cell periphery and in the filopodia; however, neither the increase in the pLCP1 signal, nor a redistribution of pLCP1 could be shown convincingly in this immunofluorescence experiment (Supplemental Fig. 4). Therefore, we cloned LCP1 constructs that were tagged with RFP to characterize the phosphorylation-dependent change of LCP1 distribution in more detail. In addition to LCP1-WT, we cloned a LCP1 mutant (LCP1-S5E) that mimics phosphorylation by exchange of Ser5 with glutamic acid as well as a nonphosphorylatable mutant (LCP1 S5A) by exchange of Ser5 with alanine. Expression of the constructs and AngIIinduced phosphorylation of RFP-tagged LCP1—similar to endogenous LCP1 - was verified in HEK293T cells (Supplemental Fig. 5).

In transiently transfected podocytes, RFP-LCP1WT was mainly localized in the cytoplasm, colocalizing, in part, with actin. In less dense cell layers, RFP-LCP1-WT colocalized with actin in the filopodia in parallel to our observations of endogenous LCP1 (Figs. $4 A$ and $5 A$ ). In cells that were transfected with the phosphomimicking mutant, S5E, we also observed LCP1-stained filopodia (Fig. 5A); however, the number of filopodia of cells that were transfected with nonphosphorylatable mutant (S5A) was reduced (Fig. $5 A$ ). To confirm this observation, we evaluated the amount and length, preferably of single cells that were transfected with the three LCP1 constructs or with control plasmid (Fig. 5B). In cells that were transfected with nonphosphorylatable S5A variant, filopodia number or length did not differ from mock-transfected cells (Fig. 5C). In contrast, transfection with the LCP1S5E variant and WT increases filopodia formation in both number and length. This indicates that LCP1 phosphorylation is crucial for filopodia formation. On the basis of these results, we conclude that AngIIinduced LCP1 phosphorylation influences cell-cell contact formation.

\section{Angll-induced lamellipodia formation is independent of LCP1 phosphorylation}

AngII-induced LCP1 redistribution was studied in more detail in live cell imaging studies of podocytes that were transiently transfected with RFP-tagged LCP1WT (Fig. 6A). Addition of water did not alter the cell shape (Fig. 6A, line 1); however, treatment with AngII (Fig. 6A, line 2) induced membrane ruffling and directed lamellipodia outgrowth at the cell periphery. Lamellipodia outgrowth that resulted in an increase in RFP-signals at the cell periphery was used to quantify the AngII effect, termed cell area enlargement (Supplemental Video 1; LCP1 WT + AngII). Ruffling activity

pan-PKC inhibitor GF109203X completely blocked AngII-induced phosphorylation of LCP1. Ratio between phosphorylated and total amount of LCP1 from 3 independent experiments (right). D) Schematic representation of the regulation of LCP1 phosphorylation downstream of AngII and AT1R in podocytes. Dotted lines from PKC include the possibility that LCP1 is phosphorylated by PKC directly or mediated by PKA or RSK. Data are means \pm sD, Student's $t$ test. $* P<0.05, * * P<0.01, * * * P<$ 0.001 . 
A
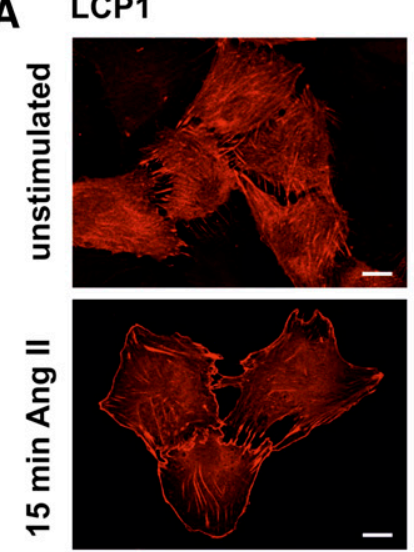

B
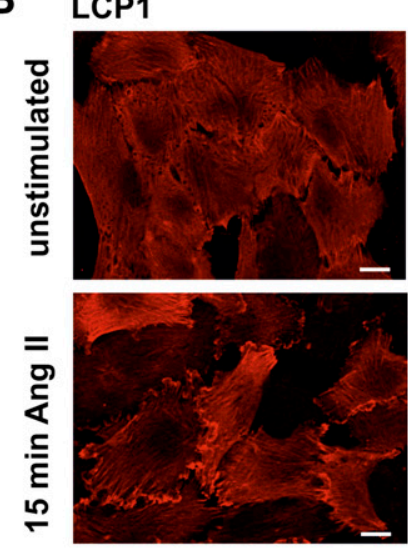

\section{Phalloidin}
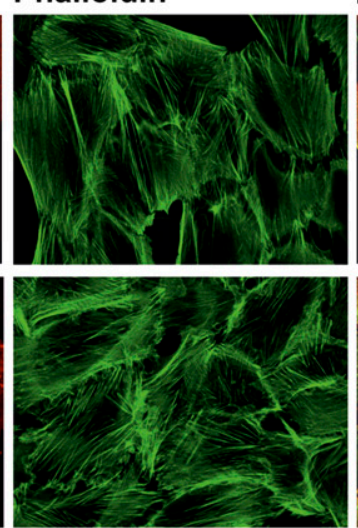

merge
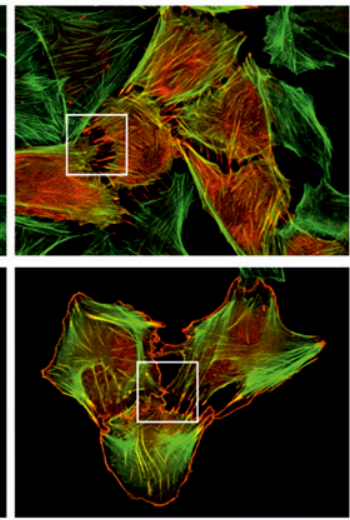

merge
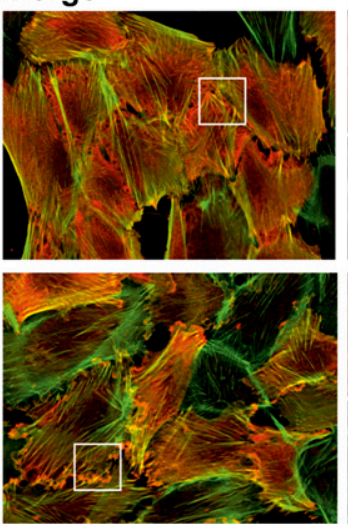

details

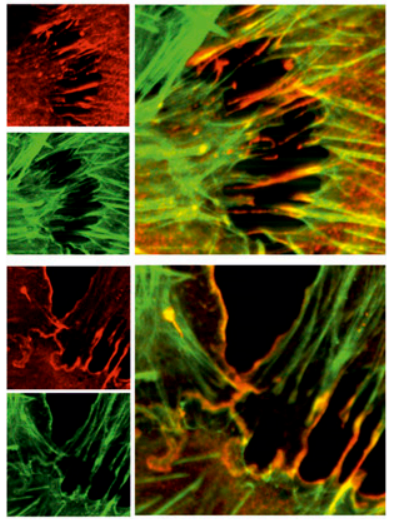

details

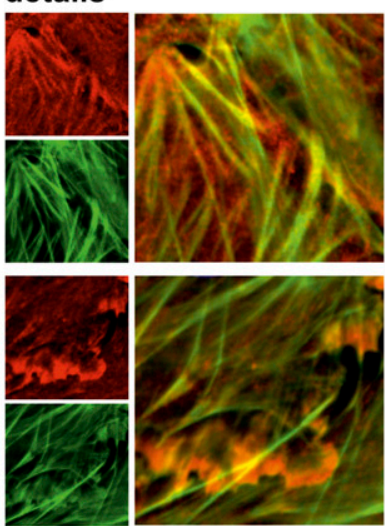

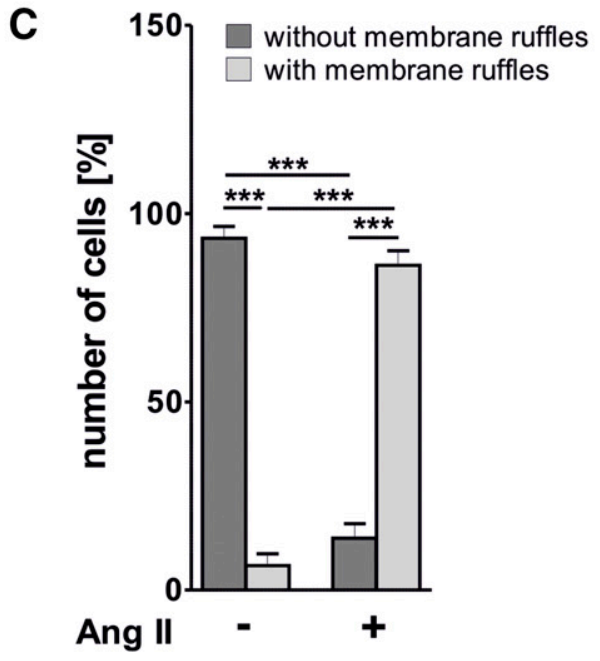

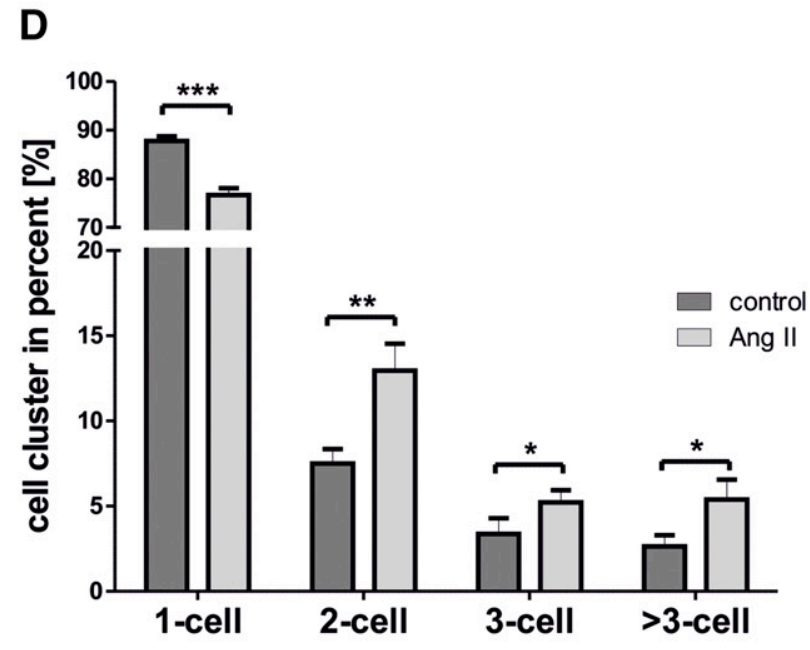

Figure 4. AngII triggers the redistribution of LCP1 localization. A) Immunofluorescent staining of endogenous LCP1 (red) and actin (phalloidin, green) before and 15 min after stimulation with AngII (100 nM) indicates an AngII-dependent redistribution of LCP1 to the cell margins in podocytes. Details illustrate the needle-like cell-cell contacts in unstimulated cells, which seemed to be broadened, in part overlapping, after AngII stimulation. $B$ ) AngII treatment leads to the formation of membrane ruffles at cell margins, especially remarkable in LCP1 staining. C) Quantification of cells with ruffled membranes evaluated from untreated cells $(n=215)$ and cells after AngII treatment $(n=169 ; 100 \mathrm{nM}, 15 \mathrm{~min}) . D$ ) Cells were cultured in suspension with and without AngII $(100 \mathrm{nM})$. Single cells and cell clusters of treated and control cells were calculated after 30 min incubation. Scale bars, $20 \mu \mathrm{m}$. Data are means $\pm \mathrm{SD}$, Student's $t$ test. $* P<0.05, * * P<0.01, * * * P<0.001$.

and cell area enlargement persisted for the entire observation period of $15 \mathrm{~min}$. This AngII-induced LCP1 redistribution could be blocked by preincubation with the AT1R-antagonist, losartan (Fig. 6A, line 3); however, preincubation with RSK inhibitor, which completely inhibited
AngII-induced LCP1 phosphorylation at Ser5 (Fig. 3A), had no influence on AngII-induced cell area enlargement (Fig. 6A, line 4). This suggested that cell area enlargement was not regulated by Ser5 phosphorylation. Similar effects on cell area enlargement were observed in cells that were 


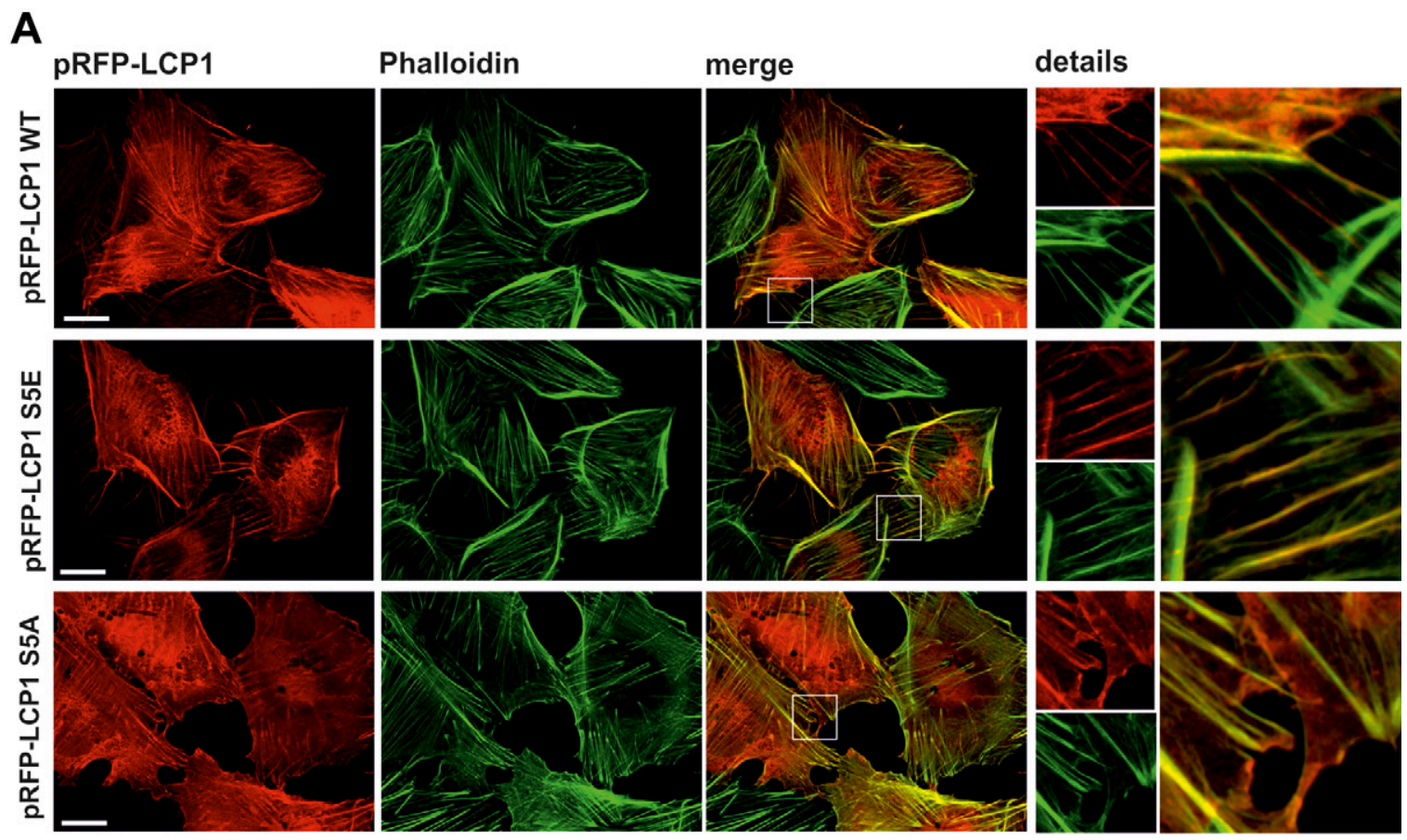

B
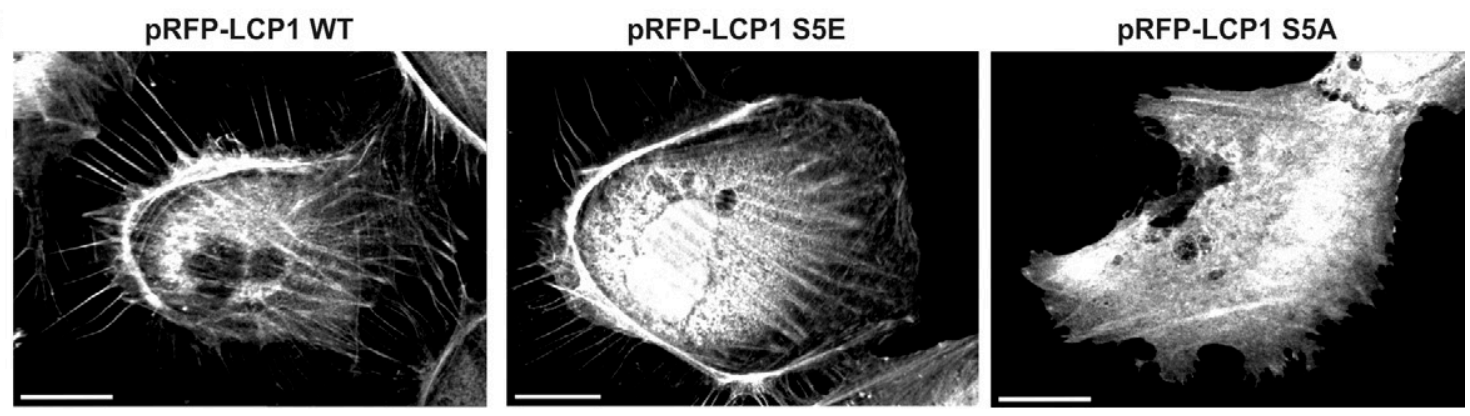

C

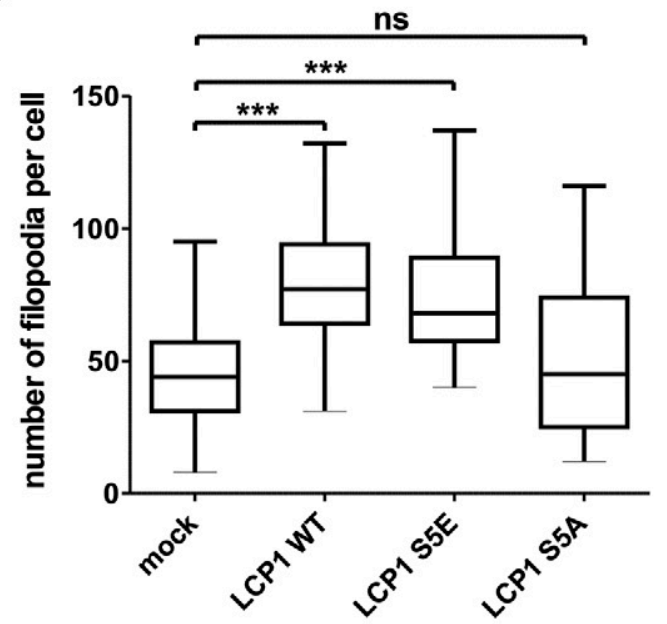

D

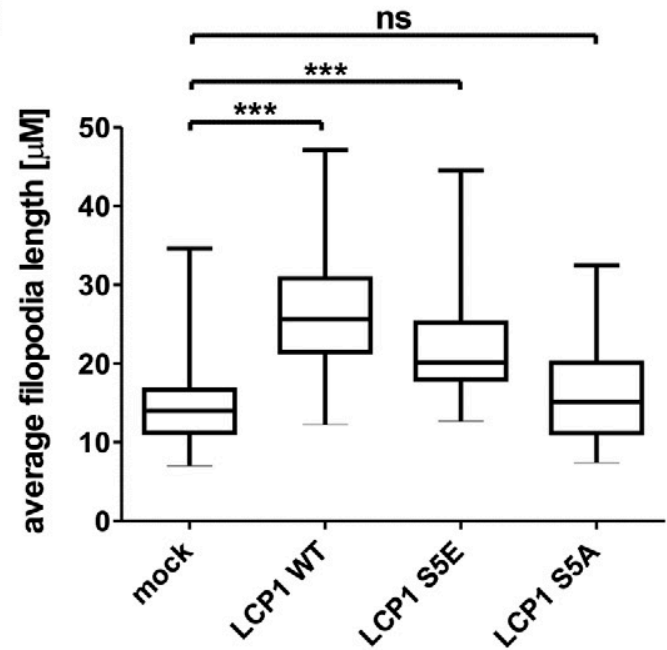

Figure 5. LCP1 phosphorylation influences filopodia formation. Podocytes were transfected with fluorescence-labeled (RFP) LCP1-WT, a LCP1 mutant (LCP1-S5E) that mimics phosphorylation and a nonphosphorylatable mutant (LCP1-S5A). A) Immunofluorescence images of podocytes that were transfected with 3 LCP1 mutants also stained against actin (phalloidin, green). Details show differences in cell-cell contact sites dependent on the transfected LCP1 mutant. B) Representative cells of podocytes that were transfected with 3 LCP1 mutants showing differences in filopodia number and length. $C, D)$ Quantification of the number and length of filopodia in podocytes that were transfected with 3 LCP1 mutants compared with control-transfected cells $(n \geq 3$, means \pm SD, Student's $t$ test). Scale bars, $20 \mu \mathrm{m} . * P<0.05, * * P<0.01, * * * P<0.001$. 
A
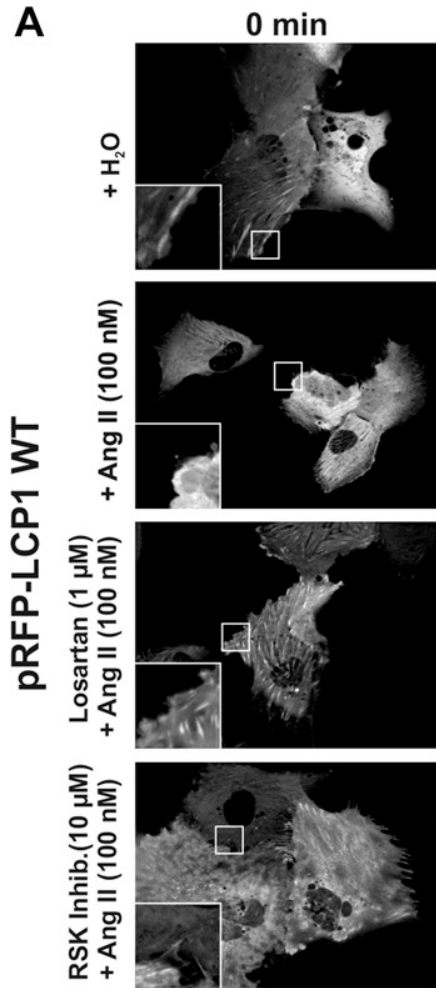

B

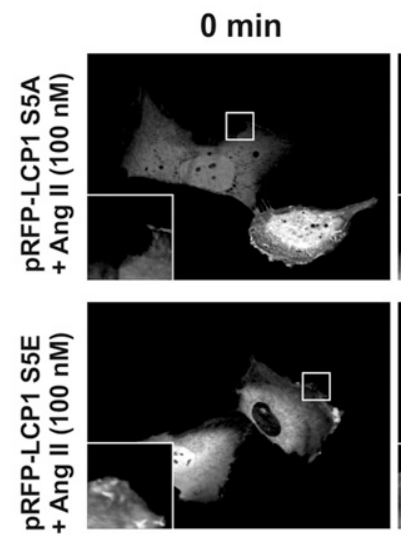

C
$2 \min$
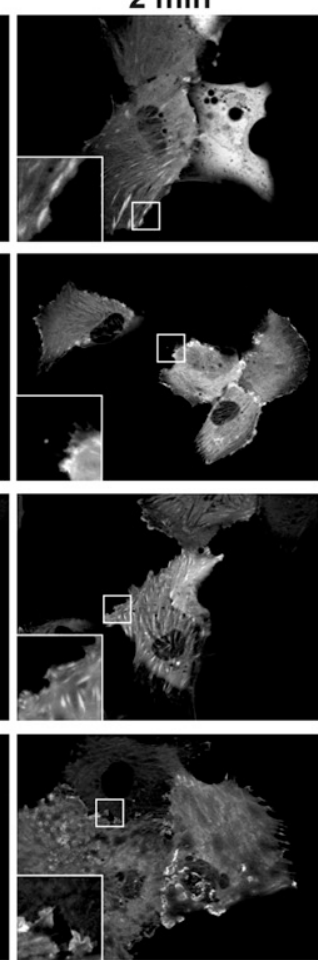

$2 \min$
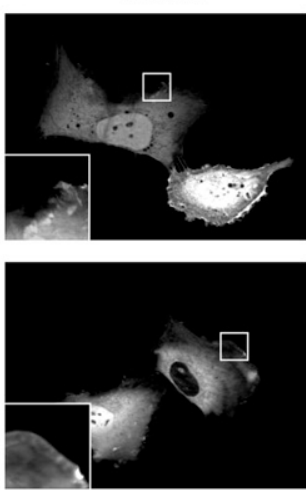

$5 \mathrm{~min}$
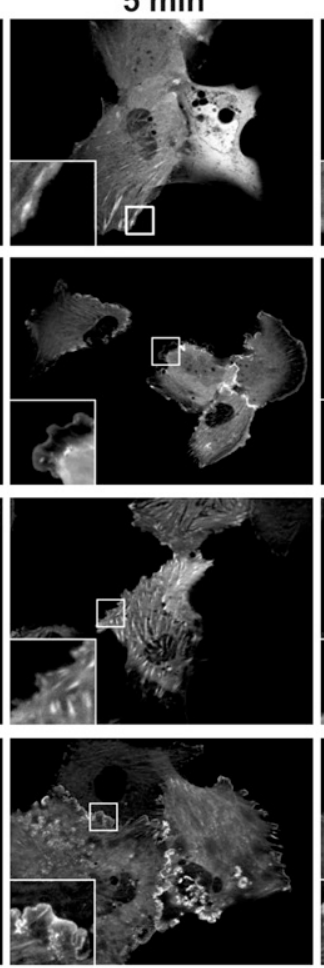

$5 \mathrm{~min}$
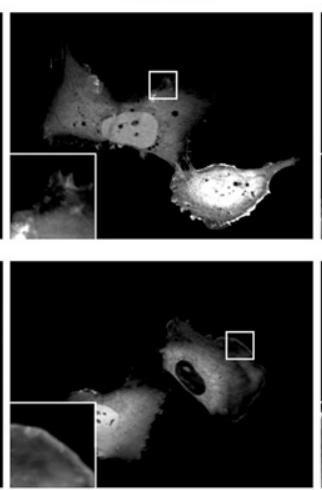

$\star * *$
$10 \mathrm{~min}$
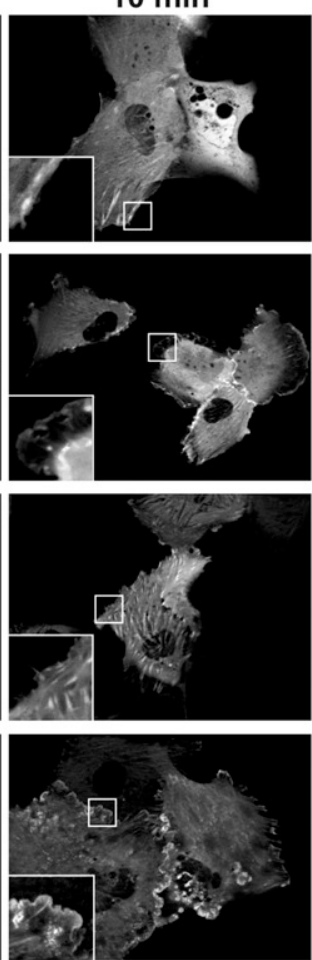

$10 \mathrm{~min}$
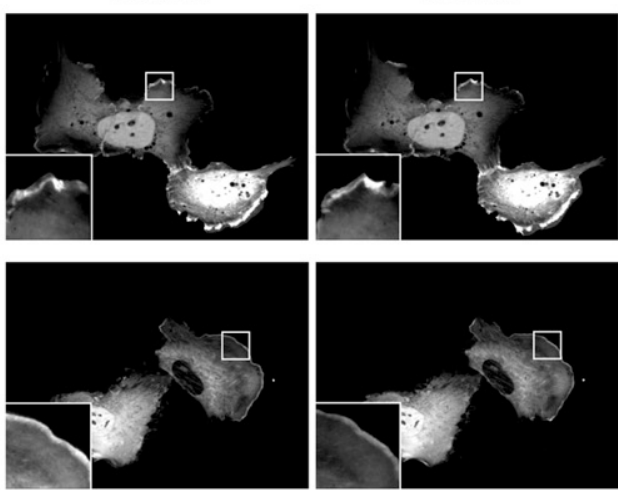

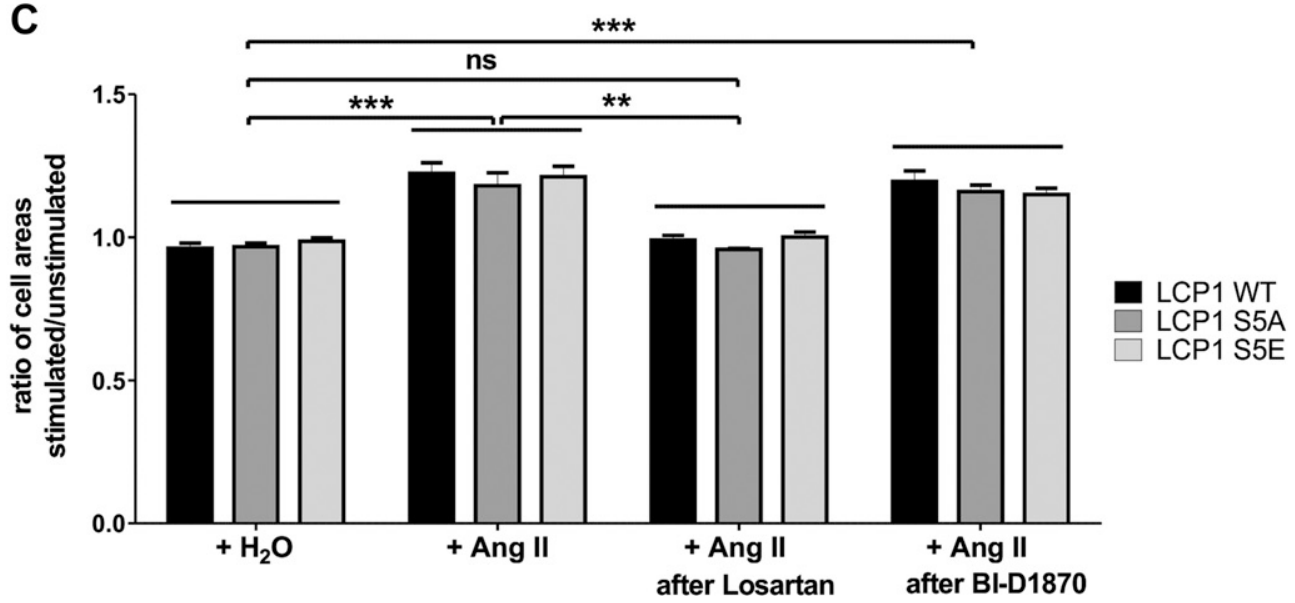

Figure 6. AngII-induced LCP1 redistribution and membrane ruffling is independent of LCP1 phosphorylation. A) Representative live cell imaging experiment of podocytes that were transiently transfected with fluorescent RFP-LCP1-WT. Stimulation of cells was performed in line 1 by adding water as control, and in lines $2-4$ by adding AngII ( $100 \mathrm{nM})$. For original movie of line 2 see the Supplemental Data. Cells in line 3 were incubated before stimulation with AT1R blocker losartan (Los; $10 \mu \mathrm{M}, 2 \mathrm{~h}$ ), and cells in line 4 were incubated with the RSK inhibitor BID1870 $(10 \mu \mathrm{M}, 3 \mathrm{~h})$. The image labeled 0 min was taken before stimulation, 
transfected with LCP1-S5A and LCP1-S5E mutants (Fig. $6 B)$ which confirmed that this effect is independent of phosphorylation.

To quantify cell area enlargement, we measured the area of cells that were transfected with RFP-tagged LCP1 mutants before AngII treatment and 15 min after AngII stimulation. Changes in these areas were summarized as the ratio of cell areas of stimulated $v s$. unstimulated cells (Fig. 6C). With this ratio as readout, an objective quantification of cell enlargement was possible, which allowed a comparison of different experiments. Here, our evaluation confirmed an AngIIinduced cell enlargement in podocytes, which is independent of LCP1 phosphorylation.

\section{$\mathrm{Ca}^{2+}$-binding EF hand motifs of LCP1 are crucial for Angll-induced lamellipodia formation}

In addition to the activation of several kinases that leads to the phosphorylation of various proteins, extracellular stimulation of AT1R with AngII increases the level of intracellular calcium $(10,11)$. LCP1 has two EF hand motifs near the $\mathrm{N}$-terminus that negatively regulate the actin bundling activity of LCP1 by calcium binding $(46,47)$. Therefore, we hypothesized that membrane ruffling and lamellipodia formation after AngII stimulation could also be regulated by the $\mathrm{Ca}^{2+}$ binding ability of LCP1 and cloned two LCP1 deletion mutants, one of which lacks the complete N-terminus (LCP1_minus EF) and the other which lacks the EF hand motifs (LCP1_phospho_minus EF; Fig. 7A). The effects of these deletions were examined in live cell imaging studies (Fig. 7B). We again used cell area enlargement as readout. In contrast to LCP1-WT, AngII stimulation did not lead to cell area enlargement in cells that expressed the deletion mutants, despite LCP1 redistribution and membrane ruffling. The presence or absence of the phosphosite made no difference. The same effect was achieved with LCP1-WT-transfected cells when intracellular and extracellular $\mathrm{Ca}^{2+}$ concentrations were reduced. Quantification of cell enlargement confirmed this observation (Fig. 7C). These results indicate that AngIIinduced lamellipodia formation in LCP1-transfected podocytes is mainly regulated by the increase in intracellular $\mathrm{Ca}^{2+}$ concentration. Additional experiments demonstrate that AngII can also regulate T-plastin in a calcium-dependent manner (Supplemental Fig. 6).

However, our data strongly indicate that LCP1-in contrast to other members of the plastin family-is regulated by 2 different AngII-dependent mechanisms. First, via activation of various serine/threonine kinases, and second, via increased $\mathrm{Ca}^{2+}$-influx, which suggests that the regulation of LCP1 is more complex than that of other members of the plastin family-I-plastin and T-plastin-that lack the phosphorylation site at the N-terminus.

Taken together, our data indicate that AngII-dependent phosphorylation of actin-associated proteins occurs via ERK, RSK, PKA, and PKC kinases. Focusing on LCP1, our study highlights that AngII can influence protein activity by different effects-Ca influx and activation of kinases-indicating that AngII influences cytoskeletal dynamics in podocytes within a complex and, presumably, finely tuned signaling network.

\section{DISCUSSION}

The fate and function of podocytes are based on their complex architecture and, in particular, on the integrity of their actin cytoskeleton (48). It has been suggested that changes in the actin cytoskeleton and intracellular $\mathrm{Ca}^{2+}$ play a major role in the morphogenesis and pathology of podocytes (49). Global reorganization of actin and, ultimately, foot process effacement are hallmarks of glomerular diseases. AngII directly affects the actin cytoskeleton of podocytes, and, in the long-term, AngII and increased RAAS contribute to the progression of glomerular injury (6). AngII depolarizes glomerular cells by leading to an increase of cytosolic calcium concentration and, in podocytes, by activation of a calcium-dependent $\mathrm{Cl}^{-}$conductance (50). Moreover, AngII induces a shift of the podocyte phenotype from a dynamically stable type to an adaptively migratory type. This is conferred among others via the influence on the actin cytoskeleton (12).

Glomerular diseases that are caused by diabetes, hypertension, or immunologic processes represent the major cause of chronic kidney disease, which affects more than $5 \%$ of the population worldwide. Therapeutic inhibition of AngII signaling via administration of AT1R blocker and angiotensin-converting enzyme inhibitors lowers mortality and may delay disease progression and, thus, is recommended for most patients with chronic kidney disease. Additional understanding of the molecular action of AngII in podocytes will lead to the identification of novel treatment strategies.

The aim of our current study was to obtain greater insight into intracellular AngII/AT1R pathway-dependent phosphorylation and, especially, to identify which kinases contribute to the signal transduction processes. Therefore, we employed an SILAC-based approach and analyzed changes in the phosphoproteome in podocytes after shortterm treatment with AngII. With this technique, weidentified 6323 independent phosphopeptides that corresponded to 2081 different proteins. More than three fourths of proteins identified in our screen have been previously found in a non-phospho-specific characterization of the mouse

whereas the other pictures were obtained at the indicated time points after stimulation. B) Representative live cell imaging experiment of podocytes that were transiently transfected with fluorescent RFP-LCP1-S5A or -S5E stimulated with AngII $(100 \mathrm{nM})$. The image labeled 0 min was taken before stimulation, whereas the other pictures were obtained at the indicated time points after stimulation. C) Quantification of cell enlargement after stimulation from live cell experiments using ImageJ. RFPlabeled cell areas at time point 0 min were determined as unstimulated values and at time point 15 min as stimulated values. The ratio of cell areas is shown $(n \geq 3$, mean $\pm \mathrm{sD}$, Student's $t$ test). $* P<0.05$, $* * P<0.01, * * * P<0.001$. 
A

LCP1 WT

EF-hands

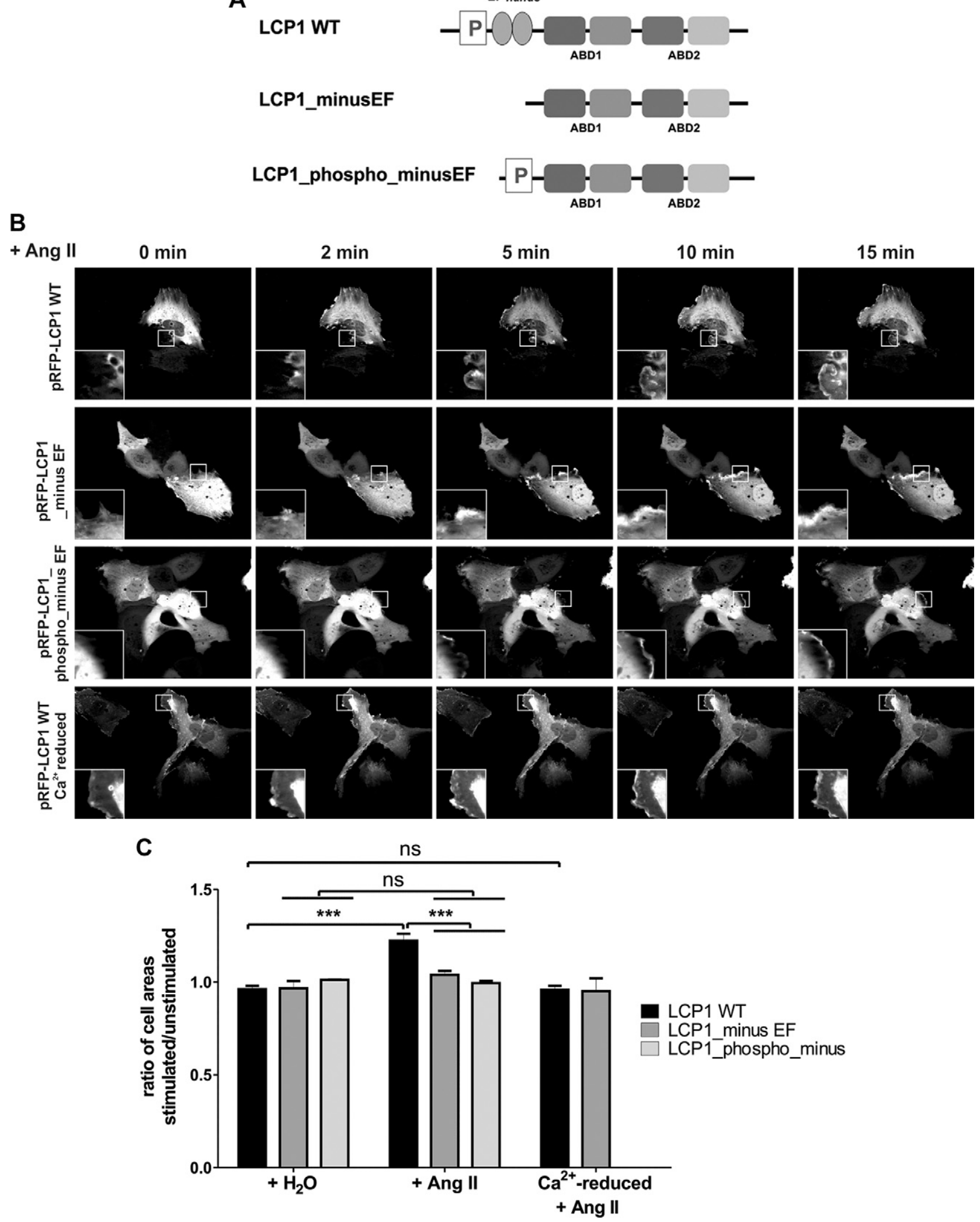

Figure 7. AngII-induced membrane ruffling is predominantly $\mathrm{Ca}^{2+}$ dependent. A) Schematic overview of LCP1 deletion mutants without EF-binding sites [actin-binding domain (ABD)]. B) Representative live cell imaging experiment of podocytes that were transiently transfected with fluorescent RFP-LCP1-WT (lines 1 and 4) or the 2 deletion mutants as indicated (lines 2 and 3). For the experiment in line 4, intracellular and extracellular $\mathrm{Ca}^{2+}$ concentration was reduced. Stimulation of cells was performed by adding AngII (100 nM). The image labeled " 0 min" was taken before stimulation, whereas the other pictures were obtained at the indicated time points after stimulation. $C$ ) Quantification of cell enlargement after stimulation from live cell experiments. RFPlabeled cell areas at time point 0 min were determined as unstimulated values and at time point 15 min as stimulated values using ImageJ. The ratio of cell areas is shown $\left(n \geq 3\right.$, means $\pm \mathrm{SD}$, Student's $t$ test). $* P<0.05,{ }^{*} P<<0.01, * * * P<0.001$. 
podocyte proteome (34), which validated the outcome of this SILAC approach. Of interest, one fourth of proteins identified in our approach are new and had not been identified in the mouse podocyte proteome, likely as a result of the phospho-enrichment of proteins of our podocyte cell line.

One hundred twenty-one of the phosphoproteins that were increased in our study were also regulated in a previous study with AT1R-overexpressing HEK293 cells, which suggests that the 323 novel proteins identified in this study could be podocyte specific (35).

A large number of identified phosphopeptides correspond to extracellular matrix proteins (Table 1). Expression of these proteins in the human kidney and their phosphorylation at extracellular residues has also been observed in prior studies (51-53); however, the significance of their increased phosphorylation as observed in cell lysates is unknown and should be addressed in future studies.

Our data demonstrate a predominant phosphorylation of actin filament-associated proteins, which is in accordance with other studies in HEK293 cells $(22,35,54)$ and indicates that AngII-induced phosphomodification of actin cytoskeleton-associated proteins could be a common feature in different cell types (Fig. 2D).

Although AngII-induced regulation of the cytoskeleton has been previously implicated in podocyte pathology, the exact mechanisms of cytoskeletal rearrangement upon AngII exposure are elusive. Podocytes are unique cells at the glomerular slit diaphragm. To fulfill their function as a filter, they require an intact and flexible actin cytoskeleton. On this basis, the strong AngII-induced increase in phosphorylation of actin-associated protein LCP1 at Ser5 (factor 4.77; Table 1) stood out among the most enriched phosphopeptides in our screen. LCP1 belongs to the $\alpha$-actinin protein family and is involved in actin cross-linking and actin bundling. Although this protein was found in several other proteomics studies (https://hpcwebapps.cit.nih.gov/ESBL/Database/PodocyteProteome/index.html), to our knowledge, ours is the first study to focus on the AngII-dependent phosphorylation of LCP1, and we have demonstrated LCP1 protein expression and its phosphorylation upon AngII treatment on the protein level in podocytes. To assess whether AngII-induced LCP1 phosphorylation was a consequence of AngII-induced intracellular $\mathrm{Ca}^{2+}$ increase, we treated podocytes with the ionophore ionomycin; however, ionomycin did not lead to increased LCP1 Ser5 phosphorylation, which suggests that a mere increase in intracellular $\mathrm{Ca}^{2+}$ is not sufficient for LCP1 phosphorylation. In contrast, treatment of podocytes with ATP resulted in LCP1 phosphorylation, which is similar to the effect of AngII. Unlike ionomycin, AngII and ATP ligands signal via activation of GPCRs that ensure well-balanced local modulation of the intracellular $\mathrm{Ca}^{2+}$ concentration. In addition to this, GPCR activation triggers multiple signal-transduction cascades, which suggests that kinases that are downstream of AngII/ AT1R lead to phosphorylation of LCP1.

Similar to that in breast cancer cells (39), LCP1 phosphorylation in podocytes was influenced by ERK, RSK, PKA, and PKC activity (Fig. 3), which suggests that LCP1 phosphorylation by these kinases is not limited to certain cell types and is also present in podocytes.
Immunofluorescence experiments demonstrated an AngII-dependent LCP1 targeting to the cell margins (Fig. 4). Moreover, membrane ruffling and alterations of cellcell contacts correlated with an increased cell-cell clustering after AngII stimulation. A correlation of LCP1 redistribution, membrane ruffling, and actin binding has previously been observed by other groups. For example, treatment of LCP1 MCF-7 breast carcinoma cells with phorbol 12-myristate 13-acetate, which is a potent activator of conventional and novel PKC family members (55), also led to increased LCP1 phosphorylation, LCP1 relocalization, and membrane ruffling (40). Furthermore, phosphomimicking LCP1-S5E was observed to accumulate in actin-rich regions in monkey kidney epithelial cells (Vero cells) (27). Ser5 phosphorylation has been described to modulate the actin dynamics in focal adhesions, which suggests that LCP1 redistribution to de novo assembled actin-rich structures depends on phosphorylation (40). However, the authors admitted that nonphosphorylatable LCP1-S5A also shifted to cell margins after treatment with phorbol 12-myristate 13-acetate, but to a lesser degree (40). This result is in line with our live cell experiments. Treatment of podocytes with an RSK inhibitor, which effectively inhibited LCP1 phosphorylation (Fig. 3A), could not suppress membrane ruffling, lamellipodia formation, and cell area enlargement after AngII stimulation in LCP1-WT-, LCP1-S5A-, or LCP1-S5E-transfected cells (Fig. 6). This indicates that membrane ruffling and lamellipodia formation do not strictly require LCP1 phosphorylation.

It is known that increased calcium concentrations negatively regulate the actin-bundling activity of LCP1 (46). It has been recently shown that LCP1 contains a switch helix structure that, in the presence of calcium, tightly binds to EF-hand motifs (47). This conformational change reduces the actin-bundling capacity of LCP1 in the presence of calcium. Our results suggest that calcium-dependent regulation of actin bundling is crucial for lamellipodia formation as the expression of the deletion mutants without calcium binding capacity or a reduction in calcium concentration prevented a successful lamellipodia formation with cell area enlargement (Fig. 7).

Otherwise we could show that LCP1 phosphorylation influences filopodia formation (Fig. 5) as in contrast to podocytes expressing the nonphosphorylatable mutant of LCP1 (LCP1-S5A) podocytes expressing the phosphorylatable (LCP1-WT) or phosphomimicking form (LCP1S5E) of LCP1 formed an increased number of prolonged filopodia. Of interest, a group investigating the influence of recombinant LCP1 single-domain Abs that bind to different regions of LCP1 also observed an influence on filopodia formation comparable to our results (45). One of the examined Abs inhibited the formation of long filopodia. This $\mathrm{Ab}$ bound to the second actin-binding domain of LCP1, which led to the conclusion that the actin-bundling activity of LCP1 plays a fundamental role in filopodia integrity. Actin bundling activity is influenced by LCP1 phosphorylation (40). In general, actin-bundling proteins, among other plastins, are involved in the assembly of filopodia (56). An accumulation of LCP1 in focal adhesions and membrane protrusions has been described previously $(27,40)$. It could be demonstrated that phosphorylation of 
LCP1 increases its association rate to actin in focal adhesions, thereby decreasing the dissociation rate of F-actin (40). In epithelial cells, filopodia are important for cell-cell contacts and cell migration (56); therefore, increased cell clustering and altered cell-cell contact formation in podocytes after AngII stimulation might be connected with changed filopodia formation as a result of LCP1 phosphorylation.

From all these results, it is tempting to speculate that both the phosphorylation of LCP1 and calcium binding influence the actin-bundling activity of LCP1, but in different ways and upon different triggers. Consequently, AngII stimulation has diverse and, in part, competitive effects on LCP1 activity, the effect of membrane ruffling and lamellipodia formation obviously overlaying the effect of filopodia formation.

Expression of LCP1 in podocytes in vivo has also been found in other proteomic studies. LCP1 expression is not over-represented in podocytes and seemed to be low (57, 58); however, a low expression level does not exclude an important role in the regulation or modulation of AngIIdependent actin cytoskeleton rearrangements in podocytes. In this context, it is of special interest that podocytes not only express LCP but also T-plastin; therefore, it will be interesting to investigate whether the expression of both plastins and/or the phosphorylation of LCP1 is increased during podocyte injury.

Considering the importance of the intact actin cytoskeleton, AngII-dependent changes in the phosphorylation of LCP1 or other actin-associated proteins, such as palladin, that facilitates G- and F-actin binding and the targeting of actin to specific foci (59) might contribute to podocyte viability or damage (Table 1 ).

Taken together, our study highlights the relevance of AngII-induced phosphorylation of actin-associated proteins and, thus, the regulation of actin dynamics in podocytes. The main phosphorylation cascades that are activated by AngII seem to be conserved, but apparently AngII signaling in podocytes is complemented by podocyte-specific signal transduction. LCP1 might act as a signal-integrating molecule and coregulator of actin dynamics upon different GPCR-dependent-in this case, AngII/AT1R-signaling cascades. Although additional studies are needed, the development of drugs that target the cytoskeletal turnover of actin-modulating proteins would be a promising approach for the treatment of diseases of the podocyte.

\section{ACKNOWLEDGMENTS}

This work was supported by grants from the German Research Foundation (DFG; Grants PA 483/16-1 and BU 1214/4-1). The authors declare no conflicts of interest.

\section{AUTHOR CONTRIBUTIONS}

L. K. Schenk, D. Wolters, T. Weide, H. Pavenstädt, and B. Vollenbröker designed research; L. K. Schenk and B. Vollenbröker analyzed data; L. K. Schenk, A. MöllerKerutt, D. Wolters, R. Klosowski, and B. Vollenbröker performed research; L. K. Schenk and B. Vollenbröker wrote the paper; E. Schaffner-Reckinger contributed a novel antibody; and all authors revised the final version of the manuscript.

\section{REFERENCES}

1. Scott, R. P., and Quaggin, S. E. (2015) Review series: the cell biology of renal filtration. J. Cell Biol. 209, 199-210

2. Fukuda, A., Wickman, L. T., Venkatareddy, M. P., Sato, Y., Chowdhury, M. A., Wang, S. Q., Shedden, K. A., Dysko, R. C., Wiggins, J. E., and Wiggins, R. C. (2012) Angiotensin II-dependent persistent podocyte loss from destabilized glomeruli causes progression of end stage kidney disease. Kidney Int. 81, 40-55

3. Wennmann, D. O., Hsu, H. H., and Pavenstädt, H. (2012) The reninangiotensin-aldosterone system in podocytes. Semin. Nephrol. 32 , 377-384

4. Schweda, F. (2015) Salt feedback on the renin-angiotensinaldosterone system. Pflugers Arch. 467, 565-576

5. Dworkin, L. D., Ichikawa, I., and Brenner, B. M. (1983) Hormonal modulation of glomerular function. Am. J. Physiol. 244, F95-F104

6. Remuzzi, G., Perico, N., Macia, M., and Ruggenenti, P. (2005) The role of renin-angiotensin-aldosterone system in the progression of chronic kidney disease. Kidney Int. Suppl. 2005, S57-S65

7. Rüster, C., and Wolf, G. (2011) Angiotensin II as a morphogenic cytokine stimulating renal fibrogenesis. J. Am. Soc. Nephrol. 22, 1189-1199

8. Kobori, H., Mori, H., Masaki, T., and Nishiyama, A. (2013) Angiotensin II blockade and renal protection. Curr. Pharm. Des. 19, 3033-3042

9. Xie, X., Liu, Y., Perkovic, V., Li, X., Ninomiya, T., Hou, W., Zhao, N., Liu, L., Lv, J., Zhang, H., and Wang, H. (2016) Renin-angiotensin system inhibitors and kidney and cardiovascular outcomes in patients with CKD: a Bayesian network meta-analysis of randomized clinical trials. Am. J. Kidney Dis. 67, 728-741

10. Eguchi, S., Frank, G. D., Mifune, M., and Inagami, T. (2003) Metalloprotease-dependent ErbB ligand shedding in mediating EGFR transactivation and vascular remodelling. Biochem. Soc. Trans. 31, 1198-1202

11. Suzuki, H., Motley, E. D., Frank, G. D., Utsunomiya, H., and Eguchi, S. (2005) Recent progress in signal transduction research of the angiotensin II type-1 receptor: protein kinases, vascular dysfunction and structural requirement. Curr. Med. Chem. Cardiovasc. Hematol. Agents 3, 305-322

12. Hsu, H. H., Hoffmann, S., Endlich, N., Velic, A., Schwab, A., Weide, T., Schlatter, E., and Pavenstädt, H. (2008) Mechanisms of angiotensin II signaling on cytoskeleton of podocytes. J. Mol. Med. (Berl.) 86, 1379-1394

13. Morley, S. C. (2013) The actin-bundling protein L-plastin supports T-cell motility and activation. Immunol. Rev. 256, 48-62

14. Wennmann, D. O., Vollenbröker, B., Eckart, A. K., Bonse, J., Erdmann, F., Wolters, D. A., Schenk, L. K., Schulze, U., Kremerskothen, J., Weide, T., and Pavenstädt, H. (2014) The Hippo pathway is controlled by angiotensin II signaling and its reactivation induces apoptosis in podocytes. Cell Death Dis. 5, e1519

15. Schulze, U., Vollenbröker, B., Braun, D. A., Van Le, T., Granado, D., Kremerskothen, J., Fränzel, B., Klosowski, R., Barth, J., Fufezan, C., Wolters, D. A., Pavenstädt, H., and Weide, T. (2014) The Vac14 interaction network is linked to regulators of the endolysosomal and autophagic pathway. Mol. Cell. Proteomics 13, 1397-1411

16. Tchapyjnikov, D., Li, Y., Pisitkun, T., Hoffert, J. D., Yu, M. J., and Knepper, M.A. (2010) Proteomic profiling of nuclei from native renal inner medullary collecting duct cells using LC-MS/MS. Physiol. Genomics 40, 167-183

17. Rinschen, M. M., Yu, M.J., Wang, G., Boja, E. S., Hoffert, J. D., Pisitkun, T., and Knepper, M.A. (2010) Quantitative phosphoproteomic analysis reveals vasopressin V2-receptor-dependent signaling pathways in renal collecting duct cells. Proc. Natl. Acad. Sci. USA 107, 3882-3887

18. Wiśniewski, J. R., and Mann, M. (2012) Consecutive proteolytic digestion in an enzyme reactor increases depth of proteomic and phosphoproteomic analysis. Anal. Chem. 84, 2631-2637

19. Thingholm, T. E., and Larsen, M. R. (2009) The use of titanium dioxide micro-columns to selectively isolate phosphopeptides from proteolytic digests. Methods Mol. Biol. 527, 57-66, xi

20. Washburn, M. P., Wolters, D., and Yates III, J. R. (2001) Large-scale analysis of the yeast proteome by multidimensional protein identification technology. Nat. Biotechnol. 19, 242-247 
21. Cox, J., and Mann, M. (2008) MaxQuant enables high peptide identification rates, individualized p.p.b.-range mass accuracies and proteome-wide protein quantification. Nat. Biotechnol. 26, 1367-1372

22. Xiao, K., Sun, J., Kim, J., Rajagopal, S., Zhai, B., Villén, J., Haas, W., Kovacs, J.J., Shukla, A. K., Hara, M. R., Hernandez, M., Lachmann, A., Zhao, S., Lin, Y., Cheng, Y., Mizuno, K., Ma'ayan, A., Gygi, S. P., and Lefkowitz, R. J. (2010) Global phosphorylation analysis of betaarrestin-mediated signaling downstream of a seven transmembrane receptor (7TMR). Proc. Natl. Acad. Sci. USA 107, 15299-15304

23. Dennis, G., Jr., Sherman, B. T., Hosack, D. A., Yang, J., Gao, W., Lane, H. C., and Lempicki, R. A. (2003) DAVID: database for annotation, visualization, and integrated discovery. Genome Biol. 4, P3

24. Douglass, J., Gunaratne, R., Bradford, D., Saeed, F., Hoffert, J. D., Steinbach, P. J., Knepper, M. A., and Pisitkun, T. (2012) Identifying protein kinase target preferences using mass spectrometry. Am. J. Physiol. Cell Physiol. 303, C715-C727

25. Hornbeck, P. V., Zhang, B., Murray, B., Kornhauser, J. M., Latham, V., and Skrzypek, E. (2015) PhosphoSitePlus, 2014: mutations, PTMs and recalibrations. Nucleic Acids Res. 43, D512-D520

26. Schenk, L. K., Schulze, U., Henke, S., Weide, T., and Pavenstadt, H. (2016) TMEM16F regulates baseline phosphatidylserine exposure and cell viability in human embryonic kidney cells. Cell Physiol. Biochem. 38, 2452-2463

27. Janji, B., Giganti, A., De Corte, V., Catillon, M., Bruyneel, E., Lentz, D., Plastino, J., Gettemans, J., and Friederich, E. (2006) Phosphorylation on Ser5 increases the F-actin-binding activity of L-plastin and promotes its targeting to sites of actin assembly in cells. J. Cell Sci. 119, 1947-1960

28. Campbell, R. E., Tour, O., Palmer, A. E., Steinbach, P. A., Baird, G. S., Zacharias, D. A., and Tsien, R.Y. (2002) A monomeric red fluorescent protein. PNAS 99, 7877-7882

29. Nilufar, S., Morrow, A. A., Lee, J. M., and Perkins, T. J. (2013) FiloDetect: automatic detection of filopodia from fluorescence microscopy images. BMC Syst. Biol. 7, 66

30. Saleem, M. A., O'Hare, M. J., Reiser, J., Coward, R. J., Inward, C. D., Farren, T., Xing, C.Y., Ni, L., Mathieson, P. W., and Mundel, P. (2002) A conditionally immortalized human podocyte cell line demonstrating nephrin and podocin expression. J. Am. Soc. Nephrol. 13, 630-638

31. Shin, S. Y., Kim, T., Lee, H. S., Kang, J. H., Lee, J.Y., Cho, K. H., and Kim, D. H. (2014) The switching role of $\beta$-adrenergic receptor signalling in cell survival or death decision of cardiomyocytes. Nat. Commun. 5, 5777

32. Humphrey, S. J., Azimifar, S. B., and Mann, M. (2015) Highthroughput phosphoproteomics reveals in vivo insulin signaling dynamics. Nat. Biotechnol. 33, 990-995

33. Ayoub, M. A., Trebaux, J., Vallaghe, J., Charrier-Savournin, F., Al-Hosaini, K., Gonzalez Moya, A., Pin, J. P., Pfleger, K. D., and Trinquet, E. (2014) Homogeneous time-resolved fluorescence-based assay to monitor extracellular signal-regulated kinase signaling in a high-throughput format. Front. Endocrinol. (Lausanne) 5, 94

34. Rinschen, M. M., Schroeter, C. B., Koehler, S., Ising, C., Schermer, B., Kann, M., Benzing, T., and Brinkkoetter, P. T. (2016) Quantitative deep mapping of the cultured podocyte proteome uncovers shifts in proteostatic mechanisms during differentiation. Am. J. Physiol. Cell Physiol. 311, C404-C417

35. Christensen, G. L., Kelstrup, C. D., Lyngsø, C., Sarwar, U., Bøgebo, R., Sheikh, S. P., Gammeltoft, S., Olsen, J. V., and Hansen, J. L. (2010) Quantitative phosphoproteomics dissection of seven-transmembrane receptor signaling using full and biased agonists. Mol. Cell. Proteomics 9, 1540-1553

36. Yao, J., Le, T. C., Kos, C. H., Henderson, J. M., Allen, P. G., Denker, B. M., and Pollak, M. R. (2004) Alpha-actinin-4-mediated FSGS: an inherited kidney disease caused by an aggregated and rapidly degraded cytoskeletal protein. PLoS Biol. 2, e167

37. Morgan, A. J., and Jacob, R. (1994) Ionomycin enhances $\mathrm{Ca}^{2+}$ influx by stimulating store-regulated cation entry and not by a direct action at the plasma membrane. Biochem. J. 300, 665-672

38. Reiser, J., von Gersdorff, G., Loos, M., Oh, J., Asanuma, K., Giardino, L., Rastaldi, M. P., Calvaresi, N., Watanabe, H., Schwarz, K., Faul, C., Kretzler, M., Davidson, A., Sugimoto, H., Kalluri, R., Sharpe, A. H., Kreidberg, J. A., and Mundel, P. (2004) Induction of B7-1 in podocytes is associated with nephrotic syndrome. J. Clin. Invest. 113, 1390-1397

39. Lommel, M. J., Trairatphisan, P., Gäbler, K., Laurini, C., Muller, A., Kaoma, T., Vallar, L., Sauter, T., and Schaffner-Reckinger, E. (2016) LPlastin Ser5 phosphorylation in breast cancer cells and in vitro is mediated by RSK downstream of the ERK/MAPK pathway. FASEB J. 30, 1218-1233

40. Al Tanoury, Z., Schaffner-Reckinger, E., Halavatyi, A., Hoffmann, C., Moes, M., Hadzic, E., Catillon, M., Yatskou, M., and Friederich, E. (2010) Quantitative kinetic study of the actin-bundling protein L-plastin and of its impact on actin turn-over. PLoS One 5, e9210

41. Sapkota, G. P., Cummings, L., Newell, F. S., Armstrong, C., Bain, J., Frodin, M., Grauert, M., Hoffmann, M., Schnapp, G., Steegmaier, M., Cohen, P., and Alessi, D. R. (2007) BI-D1870 is a specific inhibitor of the p90 RSK (ribosomal S6 kinase) isoforms in vitro and in vivo. Biochem. J. 401, 29-38

42. Davies, S. P., Reddy, H., Caivano, M., and Cohen, P. (2000) Specificity and mechanism of action of some commonly used protein kinase inhibitors. Biochem. J. 351, 95-105

43. Poppe, H., Rybalkin, S. D., Rehmann, H., Hinds, T. R., Tang, X. B., Christensen, A. E., Schwede, F., Genieser, H. G., Bos, J. L., Doskeland, S. O., Beavo, J. A., and Butt, E. (2008) Cyclic nucleotide analogs as probes of signaling pathways. Nat. Methods 5, 277-278

44. Toullec, D., Pianetti, P., Coste, H., Bellevergue, P., Grand-Perret, T., Ajakane, M., Baudet, V., Boissin, P., Boursier, E., Loriolle, F., Duhamel, L., Charon, D., and Kirilovsky, J. (1991) The bisindolylmaleimide GF 109203X is a potent and selective inhibitor of protein kinase C. J. Biol. Chem. 266, 15771-15781

45. Delanote, V., Vanloo, B., Catillon, M., Friederich, E., Vandekerckhove, J., and Gettemans, J. (2010) An alpaca single-domain antibody blocks filopodia formation by obstructing L-plastin-mediated F-actin bundling. FASEB J. 24, 105-118

46. Namba, Y., Ito, M., Zu, Y., Shigesada, K., and Maruyama, K. (1992) Human $\mathrm{T}$ cell L-plastin bundles actin filaments in a calciumdependent manner. J. Biochem. 112, 503-507

47. Ishida, H., Jensen, K. V., Woodman, A. G., Hyndman, M. E., and Vogel, H. J. (2017) The calcium-dependent switch helix of L-plastin regulates actin bundling. Sci. Rep. 7, 40662

48. Brähler, S., Yu, H., Suleiman, H., Krishnan, G. M., Saunders, B. T. Kopp, J. B., Miner, J. H., Zinselmeyer, B. H., and Shaw, A. S. (2016) Intravital and kidney slice imaging of podocyte membrane dynamics. J. Am. Soc. Nephrol. 27, 3285-3290

49. Greka, A., and Mundel, P. (2012) Calcium regulates podocyte actin dynamics. Semin. Nephrol. 32, 319-326

50. Gloy, J., Henger, A., Fischer, K. G., Nitschke, R., Mundel, P., Bleich, M., Schollmeyer, P., Greger, R., and Pavenstädt, H. (1997) Angiotensin II depolarizes podocytes in the intact glomerulus of the rat. J. Clin. Invest. 99, 2772-2781

51. Harding, S. D., Armit, C., Armstrong, J., Brennan, J., Cheng, Y., Haggarty, B., Houghton, D., Lloyd-MacGilp, S., Pi, X., Roochun, Y., Sharghi, M., Tindal, C., McMahon, A. P., Gottesman, B., Little, M. H., Georgas, K., Aronow, B. J., Potter, S. S., Brunskill, E. W., Southard-Smith, E. M., Mendelsohn, C., Baldock, R. A., Davies, J. A., and Davidson, D. (2011) The GUDMAP database-an online resource for genitourinary research. Development 138, 2845-2853

52. McMahon, A. P., Aronow, B. J., Davidson, D. R., Davies, J. A., Gaido, K. W., Grimmond, S., Lessard, J. L., Little, M. H., Potter, S. S., Wilder, E. L., and Zhang, P.; GUDMAP project. (2008) GUDMAP: the genitourinary developmental molecular anatomy project. J. Am. Soc. Nephrol. 19, 667-671

53. Famulski, K. S., Reeve, J., de Freitas, D. G., Kreepala, C., Chang, J., and Halloran, P. F. (2013) Kidney transplants with progressing chronic diseases express high levels of acute kidney injury transcripts. Am. J. Transplant. 13, 634-644

54. Courcelles, M., Frémin, C., Voisin, L., Lemieux, S., Meloche, S., and Thibault, P. (2013) Phosphoproteome dynamics reveal novel ERK1/2 MAP kinase substrates with broad spectrum of functions. Mol. Syst. Biol. 9, 669

55. Ron, D., and Kazanietz, M. G. (1999) New insights into the regulation of protein kinase Cand novel phorbol ester receptors. FASEBJ. 13, 1658-1676

56. Khurana, S., and George, S. P. (2011) The role of actin bundling proteins in the assembly of filopodia in epithelial cells. Cell Adhes. Migr. 5, 409-420

57. Rinschen, M. M., Grahammer, F., Hoppe, A. K., Kohli, P., Hagmann, H., Kretz, O., Bertsch, S., Höhne, M., Göbel, H., Bartram, M. P., Gandhirajan, R. K., Krüger, M., Brinkkoetter, P. T., Huber, T. B., Kann, M., Wickström, S. A., Benzing, T., and Schermer, B. (2017) YAP-mediated mechanotransduction determines the podocyte's response to damage. Sci. Signal. 10, eaaf8165

58. Huling, J. C., Pisitkun, T., Song, J. H., Yu, M. J., Hoffert, J. D., and Knepper, M. A. (2012) Gene expression databases for kidney epithelial cells. Am. J. Physiol. Renal Physiol. 302, F401-F407

59. Azatov, M., Goicoechea, S. M., Otey, C.A., and Upadhyava, A. (2016) The actin crosslinking protein palladin modulates force generation and mechanosensitivity of tumor associated fibroblasts. Sci. Rep. 6, 28805

Received for publication February 17, 2017. Accepted for publication July 17, 2017. 


\section{THE}
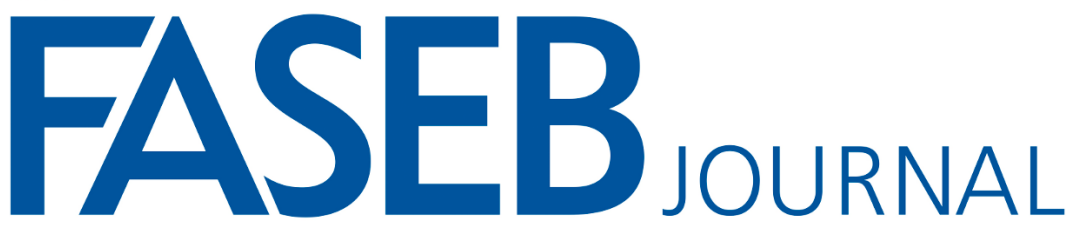

The Journal of the Federation of American Societies for Experimental Biology

\section{Angiotensin II regulates phosphorylation of actin-associated proteins in human podocytes}

Laura K. Schenk, Annika Möller-Kerutt, Rafael Klosowski, et al.

FASEB J published online August 2, 2017

Access the most recent version at doi:10.1096/fj.201700142R

Supplemental http://www.fasebj.org/content/suppl/2017/08/02/fj.201700142R.DC1

Material

Subscriptions Information about subscribing to The FASEB Journal is online at

http://www.faseb.org/The-FASEB-Journal/Librarian-s-Resources.aspx

Permissions Submit copyright permission requests at:

http://www.fasebj.org/site/misc/copyright.xhtml

Email Alerts Receive free email alerts when new an article cites this article - sign up at http://www.fasebj.org/cgi/alerts

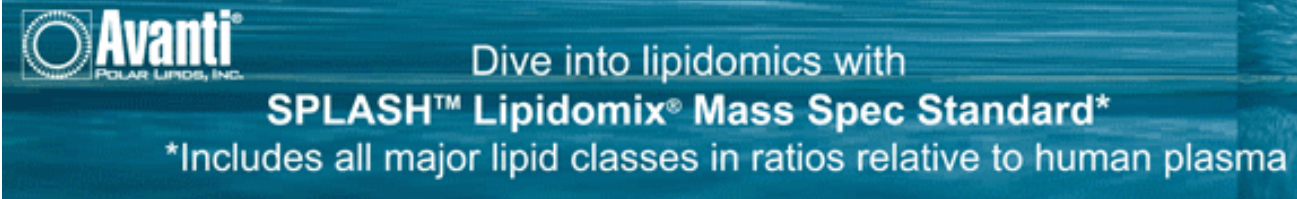

C) FASEB 